\title{
Prevention of rotavirus gastroenteritis in infants and children: rotavirus vaccine safety, efficacy, and potential impact of vaccines
}

This article was published in the following Dove Press journal:

Biologics:Targets \& Therapy

29 July 2010

Number of times this article has been viewed

\author{
Aruna Chandran' \\ Sean Fitzwater' \\ Anjie Zhen ${ }^{2}$ \\ Mathuram Santosham' \\ 'Department of International \\ Health, Division of Health Systems, \\ ${ }^{2}$ Department of Molecular \\ Microbiology and Immunology, Johns \\ Hopkins Bloomberg School of Public \\ Health, Baltimore, MD, USA
}

\begin{abstract}
Rotavirus infection is the most common cause of severe gastroenteritis globally, with greater than $86 \%$ of deaths occurring in low-income and middle-income countries. There are two rotavirus vaccines currently licensed in the United States and prequalified by the World Health Organization. RV1 is a monovalent attenuated human rotavirus strain, given orally in two doses. RV5 is a pentavalent human-bovine reassortant rotavirus vaccine, given orally in three doses. A third rotavirus vaccine, LLV, is a lamb rotavirus strain given orally as a single dose, which is currently available only in China. RV1 and RV5 have been shown to be highly efficacious in developed countries, and initial results from trials in Africa and Asia are promising as well. At least three other vaccines are in development, which are being developed by manufacturers of developing countries. Further studies are needed to clarify issues including administration of oral rotavirus vaccines with breastfeeding and other oral vaccines, and alterations in dosing schedule. Using new data on global diarrheal burden, rotavirus is estimated to cause 390,000 deaths in children younger than 5 years. Should rotavirus vaccines be introduced in the routine immunization programs of all countries, a potential of 170,000 deaths could be prevented annually. The largest impact on mortality would be seen in low-income and middle-income countries, despite poor immunization coverage and lower efficacy. Therefore, international efforts are needed to ensure that rotavirus vaccines reach the populations with highest burden of rotavirus disease.
\end{abstract}

Keywords: vaccination, mortality, rotavirus, gastroenteritis

\section{Introduction \\ Epidemiology}

Rotavirus infection is the most common cause of severe diarrhea globally, resulting in an estimated 114 million episodes of gastroenteritis, 24 million outpatient visits, and 2.4 million hospitalizations each year. ${ }^{1}$ In total, there were over 500,000 deaths attributed to rotavirus in 2004 , resulting in $5 \%$ of all deaths in children $<5$ years of age. . $^{2,3}$ The rate of rotavirus illness is similar in both developed and developing countries; in all settings, rotavirus is responsible for approximately $39 \%$ of hospitalizations due to diarrhea regardless of a country's income status. ${ }^{4}$ However, the burden of mortality is almost entirely in developing countries where access to care is limited and risk factors for disease are high. Every year, greater than $86 \%$ of deaths occur in Asia and sub-Saharan Africa, whereas less than 1,000 rotavirus deaths occur in high-income countries. ${ }^{3}$

Rotavirus gastroenteritis occurs almost exclusively in infants and children, with nearly every child having been infected by the age of 5 years. ${ }^{5}$ The majority of serious infections occur between 4 and 24 months of age, although the peak age of serious
Correspondence: Aruna Chandran Health and Pediatrics, Johns Hopkin Bloomberg School of Public Health, 615 N Wolfe St., Ste. E8622, Baltimore, MD 21205 , USA

Tel + I-4I 0-502-3946

Fax + I-443-283-4048

Email archandr@jhsph.edu 
disease varies globally. ${ }^{6}$ In developing countries, the mean age of symptomatic rotavirus infection is between 6 and 9 months while industrialized countries have a median age between 9 and 15 months. ${ }^{7}$ Older children are protected from serious disease by previous exposure and apparent infection: if it occurs, it is usually mild. ${ }^{8}$ Similarly, disease can occur in neonates but is typically mild or asymptomatic due to protection from maternal antibodies. ${ }^{5,9}$ Rotavirus infection shows strong seasonal variation; in temperate high-income countries, rotavirus disease occurs most often during the winter, whereas seasonality is less pronounced in tropical and low-income countries. ${ }^{7}$

\section{Biology}

Rotaviruses are nonenveloped viruses of the genus Reoviridae. ${ }^{10}$ The virus is characterized by a double-stranded RNA genome composed of 11 segments, which encode for six structural and six nonstructural proteins. ${ }^{10,11}$ Rotavirus particles are icosahedrons, 70-75 $\mathrm{nm}$ in diameter, composed of three concentric layers of structural proteins: the core, an inner capsid, and an outer capsid. The outer capsid is composed of a VP7 coating with VP4 spikes protruding from the viral surface. ${ }^{11}$ This layer is the most antigenically important portion of the virus, with the VP7 glycoprotein (G-type antigen) and VP4 protease-sensitive protein (P-type antigen) being the major immunological targets of the human immune system. ${ }^{11}$ The inner capsid is composed solely of VP6. Based on the antigenic properties of VP6, rotaviruses are broken into 7 serogroups, denoted A-G. Serogroup A is the only serogroup that commonly causes human disease. ${ }^{10,12}$ Conventionally, rotavirus strains are denoted by the P serotype name first, followed by its genotype in brackets, followed by the G-type. ${ }^{13}$

\section{Serotype variation}

Evolutionary pressures have led to a diversity of VP4 and VP7, resulting in over $19 \mathrm{G}$ types, 28 [P] types, and over
$40 \mathrm{G}$ and $\mathrm{P}$ antigen combinations observed in human disease (Table 1). ${ }^{11,12}$ Globally, six G + P combinations (P [8]G1, P[4] G2, P[8]G3, P[8]G4, P[8]G9, and P[6]G9) account for $>80 \%$ of rotavirus disease in all regions with the exception of Africa. ${ }^{12}$ Prior to vaccine introduction, $\mathrm{P}[8] \mathrm{G} 1$ was the most common strain globally, accounting for $72 \%-82 \%$ of all rotavirus disease in North America, Europe, and Oceania and for $23 \%-34 \%$ of strains isolated in South America, Asia, and Africa. ${ }^{12}$ Currently, P types 4, 6, 8, and 9 account for $>95 \%$ of disease regardless of region. More diversity exists in G-type, with $1-4,8$, and 9 accounting for $>95 \%$ of disease. Notably, genotype distribution is not constant in any region; substantial variation occurs over time and within countries. ${ }^{14,15}$

\section{Transmission and pathogeneses}

Rotavirus is believed to be transmitted via the fecal oral route, close personal contact, and contact with contaminated environmental sources. However, the prevalence of rotavirus in high-income countries despite improved sanitation suggests that nonfecal routes play a role in transmission. Rotavirus has been identified being shed from the oropharynx of children with symptoms of upper respiratory track disease, both with and without apparent gastrointestinal disease; ${ }^{16}$ respiratory droplets may be an important source of transmission. ${ }^{17,18}$

Upon ingestion, the rotavirus targets the epithelial lining of the intestine. ${ }^{11}$ During viral replication, the segments of the viral genome are disassociated from viral proteins and one another; this allows reassortment of genotypes in cells infected with more than one strain of rotavirus. ${ }^{19}$ Rotavirus disrupts the normal functioning of the gastrointestinal mucosa through a number of mechanisms; ${ }^{11}$ the most potent is the viral enterotoxin NSP4, which alters the permeability of the gut mucosa by weakening the tight junctions between cells, disrupting the cytoskeleton of the infected cells, increasing the secretion of chlorine ions, and stimulating the gut motility through the enteric nervous system. ${ }^{20}$ This

Table I Regional distribution of rotavirus serotypes

\begin{tabular}{|c|c|c|c|c|c|c|}
\hline Serotype & Africa, \% & Asia, \% & Europe, \% & $\begin{array}{l}\text { North } \\
\text { America, \% }\end{array}$ & Oceania, \% & $\begin{array}{l}\text { South } \\
\text { America, \% }\end{array}$ \\
\hline P[8]GI & 23 & 34 & 72 & 73 & 82 & 34 \\
\hline$P[4] G 2$ & 2 & 13 & 9 & II & 13 & 23 \\
\hline P[8]G3 & 21 & 1 & 2 & 6 & 1 & 2 \\
\hline P[8]G4 & 4 & 20 & 11 & I & 2 & 9 \\
\hline P[8]G9 & 5 & 5 & 3 & I & 1 & 15 \\
\hline$P[6] G 9$ & 2 & 7 & I & 2 & 0 & 1 \\
\hline Other & 16 & 6 & I & I & 0 & 5 \\
\hline Unusual & 27 & 14 & I & 5 & 0 & 11 \\
\hline
\end{tabular}

Note: Copyright $@$ 2005. Adapted with permission from Santos N, Hoshino Y. Global distribution of rotavirus serotypes/genotypes and its implication for the development and implementation of an effective rotavirus vaccine. Rev Med Virol. 2005; 15:29-56. 
causes in an uncontrolled outflux of water into the intestinal lumen, resulting in profuse diarrhea.

\section{Clinical disease}

Rotavirus disease is most commonly characterized by acute gastroenteritis. After an incubation period of 1-3 days, rotavirus infections present with symptoms common to many enteric pathogens: profuse watery diarrhea, vomiting, and fever. ${ }^{21}$ The severity of symptoms varies but on average is more severe than other viral enteric pathogens; ${ }^{5,22}$ although rotavirus only accounts for $6 \%-8 \%$ of community diarrhea cases, it accounts for $25 \%-40 \%$ of diarrheal cases requiring hospitalization. ${ }^{6}$ Rotavirus infections are not invasive and do not elicit a destructive inflammatory response; as a result, dysentery does not occur with rotavirus infections. Diarrhea typically lasts from 4 to 7 days. ${ }^{19}$ Virus-specific diagnostic tests and treatment are not necessary as symptoms typically resolve within a week of disease onset. ${ }^{23}$ However, supportive care, primarily rapid rehydration, is critical to preventing complications.

\section{Complications}

The most common complication associated with rotavirus infection is dehydration. The symptoms of mild and moderate dehydration, not specific to rotavirus, are restlessness, irritability, decreased skin turgor, sunken fontanelle (in infants), sunken eyes, and thirst. ${ }^{24}$ Severe dehydration is characterized by reduced or altered consciousness, lack of urine output, low blood pressure, weak quickened pulse, cool moist extremities, and peripheral cyanosis. ${ }^{25}$

Malnutrition and diarrhea form a destructive cycle in children and as the most common diarrheal pathogen in infants, rotavirus plays an important role in this cycle. Malnutrition increases the susceptibility of children to future gastrointestinal infections, and diarrhea disrupts the gut's ability to absorb nutrients, leading to an exasperation of malnutrition. As a result, $61 \%$ of children who die of diarrhea have malnutrition as an underlying risk factor. ${ }^{26}$ Furthermore, malnutrition caused by diarrhea leads to significant physical and mental growth shortfalls that negatively affect children throughout their lives, ${ }^{27}$ including negative impacts on school performance. ${ }^{28,29}$ Nutritional support is a critical component of ameliorating the short-term and long-term consequences of rotaviral, as well as other diarrhea diseases.

\section{Treatment}

Dehydration is responsible for $>90 \%$ of deaths from infectious diarrhea. ${ }^{30}$ Treatment for rotavirus gastroenteritis, as with the majority of infectious watery diarrhea, is supportive; children should receive appropriate hydration and nutritional support. Since the 1970s, the World Health Organization (WHO) has recommended the use of oral rehydration solution (ORS) for the treatment of dehydration; the worldwide extensive use of this solution saved millions of lives. In the early 1990s, multiple laboratory and clinical studies showed that reducing the osmolarity of ORS resulted in increased intestinal water absorption compared with standard ORS. A meta-analysis of trials of low-osmolarity ORS for acute diarrhea in children found that there was a $20 \%$ reduction in stool output, a $30 \%$ reduction in vomiting, and nearly a $40 \%$ reduction in the need for unscheduled intravenous treatment in patients receiving the low-osmolarity ORS compared with those receiving original ORS. ${ }^{31}$ The current WHO recommendation is for low-osmolarity ORS (245 mOsm/L) with $75 \mathrm{mmol} / \mathrm{L}$ each of sodium and glucose. In cases of severe dehydration in which the child is obtunded or unable to drink, intravenous or intraosseous fluids should be used for initial management, with the institution of ORS as soon as possible.

Until the 1970s, the medical community endorsed the belief that feeding should be withheld during diarrhea in order to "rest the gut". In the 1980s, a series of studies demonstrated that continued feeding during a diarrheal episode is safe and improves outcome. ${ }^{32-37}$ Based on these studies, the WHO incorporated early refeeding into their recommendations for diarrhea treatment. ${ }^{38}$

Deficiency of zinc can result in diminished immune response and healing. Although the role of zinc supplementation in rotavirus diarrhea has not been evaluated separately, studies in developing countries have shown that zinc supplementation, when given in addition to ORS, is highly effective in decreasing the duration and severity of diarrheal episodes. ${ }^{39-41}$ Administration of zinc along with ORS led to a decrease in hospitalizations for diarrhea, as well as other illnesses, in two large-scale studies. ${ }^{42,43}$ In Bangladesh, Baqui et $\mathrm{al}^{42}$ reported a $24 \%$ reduction in the diarrhea hospitalization rate (95\% confidence interval [CI]: 0.59-0.96) and resulted in an overall decrease in mortality (risk ratio $=0.49 ; 95 \% \mathrm{CI}$ : 0.25-0.94). Therefore, in developing country settings, the WHO recommends the daily use of zinc supplementation for 10-14 days with every episode of acute diarrhea.

Antimicrobial therapy should be used only in specific cases of infectious diarrhea and in general do not have a role in the treatment of rotavirus gastroenteritis. Probiotics, microorganisms believed to restore microbial balance in the gastrointestinal tract, may have a role in the treatment of diarrhea by enhancing the immune response or providing 
a competitive blockage of pathogen receptor sites. In a meta-analysis of seven clinical trials, Lactobacillus GG (LGG) was shown to reduce the duration of rotavirus diarrhea by 2.1 days (95\% CI: $3.6-0.6) ;{ }^{44}$ however, a recent trial in rural India did not show any efficacy. ${ }^{45}$ Saccharomyces boulardii and Lactobacillus reuteri have also shown beneficial effects for rotavirus gastroenteritis. ${ }^{46}$ Additional studies are needed to further define the necessary dose and duration of treatment, particularly in developing country settings.

Several over-the-counter and prescription antimotility (eg, loperamide), antisecretory (eg, racecadotril), and toxin-binding agents (eg, cholestyramine) are available for symptomatic relief of diarrhea. ${ }^{47-49}$ Because of the limited evidence and uncertain side-effect profiles, most experts do not recommend the use of these agents, particularly for pediatric patients. ${ }^{50,51}$ Nitazoxanide, an antiprotazoal/antihelminthic drug, was shown to reduce the duration of rotavirus diarrhea from 75 hours in the placebo group to 31 hours in the intervention group $(P=0.0137)$ in an Egyptian trial of children hospitalized with severe rotavirus gastroenteritis. ${ }^{52}$ A more recent single-blind trial in Bolivia also showed that duration of diarrhea was reduced from 79 hours to 54 hours $(P=0.009)$ with nitazoxanide. ${ }^{53}$ Further studies will be needed to fully evaluate the safety and efficacy of nitazoxanide as a treatment for rotavirus gastroenteritis.

Although the morbidity and mortality from rotavirus gastroenteritis differ across socioeconomic strata, rates of illness are similar across developed and developing country settings. This indicates that hygiene and sanitation improvements, which have been credited with reducing incidence of most causes of infectious diarrhea in developed countries, are unlikely to prevent rotavirus disease significantly. ${ }^{2}$ Therefore, prevention in the form of vaccines is essential for the control of rotavirus disease.

\section{Rotavirus vaccines \\ Biological basis of vaccinology}

Protection against rotavirus infection has been associated with the presence of antirotavirus IgA antibodies in the gastrointestinal mucosal surface. ${ }^{54}$ Although the IgA response is often used to measure vaccine immune response, levels of serum rotavirus IgA antibody do not always correlate with levels of IgA antibody in the gut. ${ }^{13}$ Presence of virus-specific IgA in feces or serum was not predictive of protection against disease in studies of the simian - human reassortant vaccine. Therefore, it remains difficult to identify the best immune correlate of protection from a rotavirus vaccine.
It is also unclear how many serotypes a rotavirus vaccine should contain. Although initial infection does not confer complete immunity to rotavirus, clinical studies show that primary infection does seem to protect against severe disease upon reinfection. For example, one study in West Africa showed that primary infection conferred 70\% (95\% CI: 29-87) protection against subsequent rotavirus diarrhea. ${ }^{55}$ Similarly, although neonatal infection does not confer complete protection against disease in future, children who had rotavirus infection as neonates appear to have less-severe disease later in childhood. This protection does not appear to be strain specific, that is, children who were infected by one rotavirus strain as neonates had less-severe diarrhea later in childhood even when infected with a different strain. ${ }^{56}$ However, protection is stronger when a child is exposed to a G-type with which they have been previously infected. ${ }^{57}$ When measuring immunologic response to natural rotavirus infection, it appears that the antibody response is higher against the infecting G-type than against other G-types. ${ }^{58}$ The benefits of a multiserotype vaccine vs a single-serotype approach to vaccine development have not been established.

Several studies have evaluated animal strain vaccine candidates, with inconsistent results. The RIT4237 bovine strain was isolated from a calf and attenuated in cell culture, and found to be immunogenic by serum immunoglobulin response in human infants. ${ }^{59}$ Although initial efficacy trials in Finland appeared positive, subsequent studies showed little or no protection against rotavirus disease. ${ }^{60-62}$ The bovine strain WC3 was isolated from a calf in Pennsylvania in 1981. This strain alone as a vaccine was not consistently protective in all efficacy trials, with protection ranging from $<10 \%$ to $76.1 \%$. ${ }^{63} \mathrm{~A}$ third strain was the rhesus rotavirus vaccine (RRV), which was isolated from a monkey and also attenuated in cell culture. Similar to RIT4237, while initial efficacy studies showed a modest level of protection, subsequent studies showed little to no effect. ${ }^{62,64}$

The poor results seen when using single-animal rotavirus strains as human vaccine candidates lead to the development of two major categories of rotavirus candidate vaccines: attenuated human rotavirus strains and recombinant (reassortant) rotaviruses containing human and animal rotavirus components. Attenuated human rotavirus strains are produced by serial passage of rotavirus strains isolated from humans in cell culture to reduce their pathogenicity. Reassortant rotavirus vaccines take advantage of the segmented rotavirus genome to create viruses that combine the RNA-encoding VP7 proteins from a human rotavirus with the remaining RNA segments of an animal rotavirus. The goal was to 
invoke the immune response to a G-type antigen from a human virus. Reassortants were initially created by coinfecting a monkey with bovine and human rotavirus and allowing the gene reassortant to occur by chance. Subsequent reassortants were created in laboratories and propagated in Vero cells. ${ }^{13}$

\section{RRV-TV}

A quadrivalent human - animal reassortant vaccine (RRV-TV) containing serotypes G1, G2, G3, and G4 was developed by the National Institutes of Health and Wyeth Laboratories (Wyeth Laboratories, Monmouth Junction, NJ). The vaccine contained the RRV strain and three simian - human reassortant strains. Several different doses were tested for safety, immunogenicity, and efficacy. In the two trials done in the United States, the dose containing $10^{5}$ plaque-forming units per strain had an efficacy against all rotavirus disease of 49\% (95\% CI: 31-63) and 57\% (95\% CI: 26-67) and against severe rotavirus disease of $80 \%$ (95\% CI: $56-91)$ and $82 \%$ (95\% CI: 29-88). ${ }^{62,65}$ There was some concern about the efficacy of the vaccine in developing countries; the higher dose vaccine when tested in Venezuela had an efficacy of $48 \%$ (95\% CI: 33-61) against all rotavirus disease and 88\% (95\% CI: 61-96) against severe rotavirus disease, which was similar to the results found in the United States. ${ }^{66}$ The vaccine was licensed in the United States in 1998 under the trade name Rotashield $^{\circledR}$ (Wyeth Lederle, Philadelphia, PA).

After several cases of intussusception were reported via the US Vaccine Adverse Event Reporting System (VAERS), a case - control investigation was conducted in 429 infants with intussusception and 1,763 matched controls. An increased risk of intussusception 3-14 days after the first dose was found (adjusted odds ratio $[\mathrm{OR}]=21.7,95 \% \mathrm{CI}$ : 9.6-48.9) ${ }^{67}$ Intussusception is not a known consequence of natural rotavirus infection. The possible explanations of why RRV-TV might cause intussusception include the following: (1) one strain in the vaccine may have been pathogenically unique from wild-type rotavirus, (2) the vaccine virus may be absorbed in the intestine in a different manner than wild type, and 3) the immune response induced by the vaccine strain might be different. ${ }^{13}$ Although the actual mechanism of the relationship between RRV-TV and intussusception is not clear, the simian strain RRV is considered the most likely causative vaccine strain. Following the results of this analysis, the use of the vaccine was discontinued. This vaccine was subsequently withdrawn from the market, and assessing the risk of intussusception has remained a key component of all subsequent rotavirus trials.

\section{RV5}

The oral human-bovine pentavalent reassortant rotavirus vaccine (Rotateq ${ }^{\circledR} ;$ Merck and Co., Whitehouse Station, NJ) consists of 5 human-bovine reassortants suspended in a fully liquid buffer-stabilized formulation (RV5). The vaccine is based on the creation of a new rotavirus strain that contains a single human virus coat protein on the viral surface, with the rest of the structural proteins from a bovine strain (WC3).

Candidate reassortants were created in vitro by coinfecting cells with WC3 and a human rotavirus strain. The progeny containing the appropriate strain mixture is selected using molecular and immunologic selection. The human-bovine reassortants for this vaccine were initially cultured using the monkey cell line MA104, and then propagated in the commonly used monkey cell line Vero using standard cellculture technique for production. The five human serotypes contained in the vaccine are G1, G2, G3, G4, and P1A[8]. The reassortant viruses with G1-G4 express the attachment protein $\mathrm{P} 7$ [5] from the bovine strain. The reassortant virus expresses the attachment protein $\mathrm{P} 1 \mathrm{~A}[8]$ from the human strain and the outer capsid protein G6 from the bovine strain. ${ }^{68}$ A comparison of three different potencies of the RV5 vaccine for safety, immunogenicity, and efficacy was conducted in Finnish infants aged 2-8 months from 1998 to $2001 .{ }^{14}$ Efficacy estimates for gastroenteritis of any severity in the first year following vaccination were $68.0 \%$ (95\% CI: 31.1-86.4), 74.3\% (95\% CI: 37.9-91.0), and 57.6\% (95\% CI: 11.8-80.9) in the high-potency, middle-potency, and low-potency groups, respectively; the middle-potency vaccine was chosen for the subsequent phase III efficacy trials.

Subsequently, clinical trials and postintroduction studies have demonstrated the efficacy of three doses of vaccine given with routine infant immunizations (Figure 1). From 2001 to 2004, the Rotavirus Efficacy and Safety Trial (REST), a double-blind, placebo-controlled, randomized trial, was conducted in over 68,000 infants in 11 countries. ${ }^{69}$ In an immunogenicity study in a small subset of the children, seroconversion rates for serum antirotavirus IgA were $95.2 \%$ (95\% CI: 91.2-97.8) in 189 vaccine recipients and $14.3 \%$ (95\% CI: 9.3-20.7) in 161 placebo recipients. In the perprotocol efficacy analysis, among 4,512 subjects, vaccine efficacy against G1-G4 gastroenteritis of any severity was 74\% (95\% CI: 66.8-79.9) and 98\% (95\% CI: 88.3-100) for severe disease in the first rotavirus season. Vaccine efficacy in the second season of RV gastroenteritis was $62.6 \%$ (95\% CI: 44.3-75.4) against any disease and 88\% (95\% CI: 49.4-98.7) against severe disease. Efficacy has been shown across several regions. In fully vaccinated infants in the 
Income level:

High
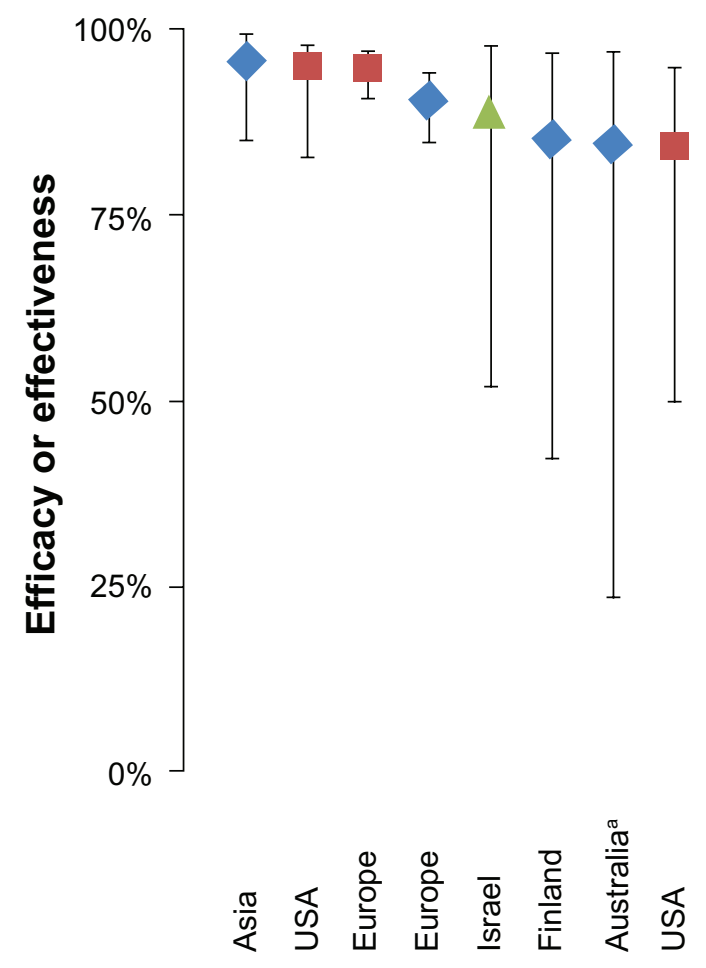

Upper
middle

Lower

middle
Low

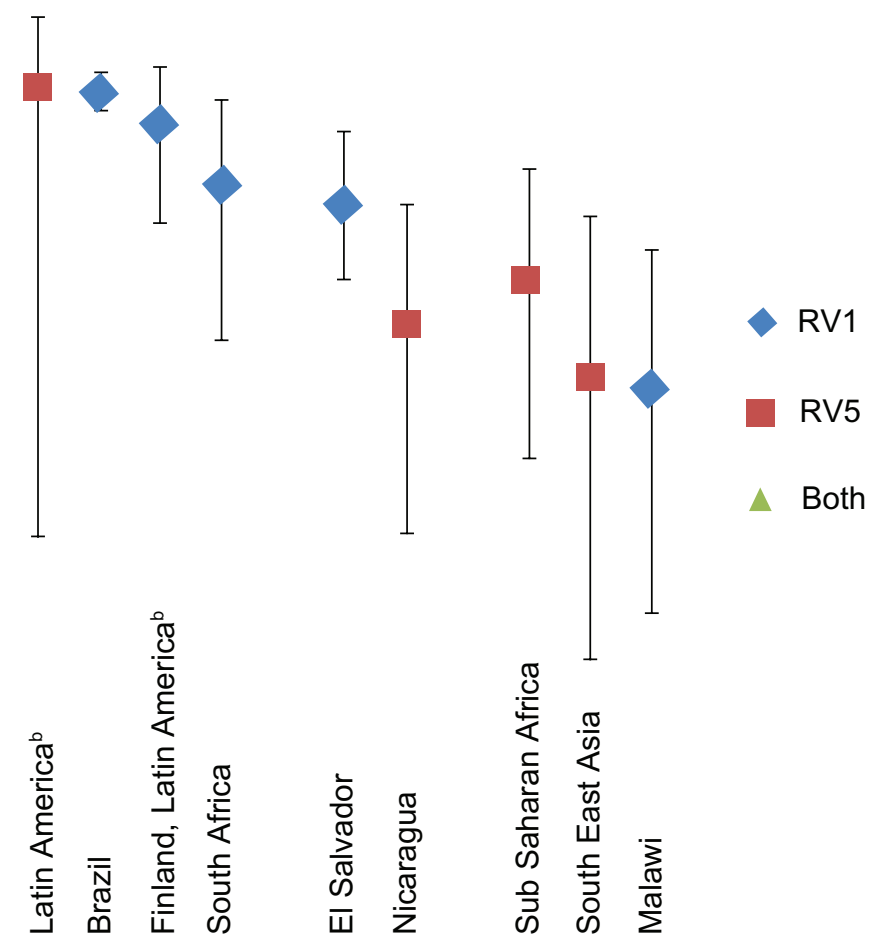

Figure I Comparison of vaccine efficacy and effectiveness estimations from clinical trials of RVI and RV5 against any serotype severe rotavirus gastroenteritis, stratified by country income status.

Note: Efficacies and effectiveness estimates are taken from the following sources (from left to right): Asia, ${ }^{86}$ USA, ${ }^{70}$ Europe, ${ }^{70}$ Europe, ${ }^{85}$ Israel, ${ }^{126}$ Finland, ${ }^{84}$ Australia, ${ }^{92}$ USA, ${ }^{75}$ Latin America, ${ }^{70}$ Brazil, ${ }^{89}$ Finland/Latin America, ${ }^{83}$ South Africa, ${ }^{87}$ El Salvador, ${ }^{93}$ Nicaragua, ${ }^{76}$ Sub-Saharan Africa and Southeast Asia, ${ }^{71}$ Malawi. ${ }^{87}$

aThis study took place in a native population characterized by diarrheal pathogens that are similar to lower income settings. ${ }^{130}$ bAlthough countries ranged from lower middle to high income, most study countries are from the upper middle income category.

REST trial, reductions in RV-associated hospitalizations and emergency department visits up to 2 years after vaccination were 94.7\% (95\% CI: 90.9-96.9) in Europe, 94.9\% (95\% CI: 84.0-98.9) in the United States, and 90.0\% (95\% CI: 29.4-99.8) in Latin America/Caribbean. ${ }^{70}$

More recently, efficacy trials were implemented in Kenya, Ghana, Mali, Bangladesh, and Vietnam to determine the protection in lower income settings, with results now available for the first year of follow-up (Figure 1). Preliminary results from the efficacy trials in Africa (Kenya, Ghana, Mali) show a three-dose efficacy of 64\% (95\% CI, 40-79) against severe rotavirus gastroenteritis. In Asia (Bangladesh and Vietnam), a three-dose efficacy of 51\% (95\% CI, 13-73) has been shown against severe rotavirus gastroenteritis. ${ }^{71}$ Safety and immunogenicity have also been demonstrated in Taiwan. ${ }^{72}$

Since its introduction in the United States in 2006, RV5 has had a dramatic impact on rotaviral disease. Postintroduction surveillance data from the Centers for Disease Control and Prevention (CDC) in the United States for the 2007-2008 and 2008-2009 seasons compared with the prevaccination period showed that the rotavirus seasons were reduced from 26 weeks to 14-17 weeks, and the peak percentage of rotavirus positive tests reduced from $43 \%$ to $17 \%-25 \% .{ }^{73}$ An evaluation of children in the United States vaccinated in the first two seasons after licensure compared with an unvaccinated cohort showed a vaccine efficacy of $100 \%$ (95\% CI: 76-100) against rotavirus gastroenteritis hospitalizations and emergency department visits. ${ }^{74}$ A case - control study in Texas showed a three-dose vaccine efficacy of $100 \%$ (95\% CI: 71-100) against severe rotavirus gastroenteritis requiring hospitalization. Vaccine effectiveness of one and two doses against hospitalization and emergency department visits was 69\% (95\% CI: 13-89) and $81 \%$ (95\% CI: $13-96)$, respectively. ${ }^{75}$ In addition, RV5 has also shown promise in low-income settings. A postintroduction evaluation in Nicaragua showed a three-dose efficacy of 58\% (95\% CI: $30-74)$ against severe rotavirus diarrhoea. ${ }^{76}$ In the 2007 rotavirus season, despite a vaccination coverage of approximately $26 \%$, hospitalizations and outpatient visits 
for diarrheal illness declined by $11 \%$ and $23 \%$, respectively, compared with prevaccination years. ${ }^{77}$

Due to the safety concerns associated with rotavirus vaccines, enhanced monitoring for possible vaccine-associated episodes of intussusceptions and other adverse effects is ongoing in many countries. The CDC published reports of postmarketing surveillance of intussusception after RV5 vaccination through September 25th, 2007. Under the assumptions that $100 \%$ of distributed doses were given and $100 \%$ of cases of intussusception were reported, the number of cases of intussusception reported through VAERS were lower than what would have been expected for the age-adjusted baseline rates at $1-7$ days after vaccination (relative risk $[\mathrm{RR}]=0.51 ; 95 \%$ CI: $0.32-0.81)$ or at $1-21$ days after vaccination $(\mathrm{RR}=0.30$; 95\% CI: 0.20-0.44). The Vaccine Safety Datalink (VSD), encompassing persons enrolled in 8 large health maintenance organizations, is also being used to monitor intussusception risk post vaccination. As of May 31st, 2008, 207, 621 doses of RV5 had been administered to infants in VSD-associated health management organizations; a total of five cases of intussusception were observed in children who had received all doses compared with an expected number of 6.75 episodes $(\mathrm{RR}=0.74){ }^{78}$

\section{RVI}

The rotavirus vaccine RV1 (Rotarix ${ }^{\circledR}$; GlaxoSmithKline, Genval, Belgium) is a monovalent vaccine composed of an attenuated human rotavirus strain G1P [8]. This parent strain was isolated during a clinical trial of an early rotavirus vaccine in $1988 .^{2}$ Although the vaccine tested in this study was eventually found to be ineffective, observation over subsequent years showed that children infected with the naturally circulating strain during the clinical trial were protected against $81 \%$ of subsequent rotavirus infections and $100 \%$ protected against severe rotavirus disease. In addition, serum antibodies produced during infection were able to neutralize G types $1-4 .^{79}$

An isolate of this strain, denoted 89-12, was serially passed in tissue culture, resulting in an attenuated viral strain that was subsequently used in clinical trials. ${ }^{2}$ Phase I and II clinical trials in Europe, the United States, and Latin America demonstrated excellent safety, immunogenicity, and efficacy. ${ }^{80}$ Early clinical trials showed an efficacy of $89 \%$ (95\% CI: 65.4-94.5) after two doses of vaccine resulting in adoption of the two-dose schedule. . $^{81,82}$

Subsequent large randomized, double-blind, placebocontrolled phase three clinical trials have demonstrated the efficacy of the vaccine given with the first and second dose of routine infant vaccination (Figure 1). A study in Finland and 11 Latin American countries following 20,169 vaccine and placebo recipients for 9-10 months, following completion of the two-dose series, found an $85 \%$ reduction $(95 \%$ CI: 71.7-92.4) in severe rotavirus gastroenteritis and a $42 \%$ (95\% CI: 29-53) reduction in hospitalization for all-cause gastroenteritis. ${ }^{83}$ Subsequent follow-up in Finland showed no reduced protection during the second rotavirus season. ${ }^{84}$ A similar but smaller trial of 3,994 infants in six European countries demonstrated efficacy across two subsequent rotavirus seasons. ${ }^{85}$ During the first rotavirus season, the vaccine recipients has $87.1 \%$ (95\% CI: 79.6-92.1) fewer rotavirus episodes and 95.8\% (95\% CI: 89.6-98.7) fewer severe rotavirus episodes. During the second season, the efficacy dropped slightly to $71.9 \%$ (95\% CI: 61.2-79.8) against any rotavirus gastroenteritis and 85.6\% (95\% CI: 75.8-91.9) against severe rotavirus disease. A study in Hong Kong, Singapore, and Taiwan following 10,708 children until 24 months of age found higher efficacy, noting a $96.1 \%(95 \%$ CI: 85.1-99.5) reduction in severe rotavirus gastroenteritis and $30.3 \%$ (95\% CI: $13.1-44.2)$ against reporting one or more episodes of severe all-cause gastroenteritis. ${ }^{86}$

To assess RV1 efficacy in low-income countries, a randomized trial was conducted in 3,166 South African and 1,773 Malawian infants. ${ }^{87}$ In South Africa, the overall efficacy was similar to what was seen in high-income country settings, with the vaccine recipients having 76.9\% (95\% CI: 56.0-88.4) fewer cases of severe rotavirus gastroenteritis and $44.1 \%$ (95\% CI: 19.8-61.0) lower incidence of all-cause severe gastroenteritis. However, in Malawian children, the efficacy of the vaccine was reduced, preventing only $49.4 \%$ (95\% CI: 19.2-68.3) of severe rotavirus gastroenteritis. This difference could not be explained by serotype differences, as both populations showed similar efficacy against G1 and non-G1 serotypes. Interestingly, despite the reduced efficacy, more disease was prevented per recipient in Malawi than in South Africa due to the higher burden of disease. In Malawi, vaccine prevented 3.9 episodes of severe rotavirus gastroenteritis per 100 vaccinated children compared with preventing 2.5 episodes per 100 vaccinated children in South Africa ${ }^{88}$ In addition, the study compared two- and three-dose schedules of RV1, with vaccine given at 6,10 , and 14 weeks or 10 and 14 weeks. No statistical difference was found in the efficacy of the vaccine in children who received two versus three doses.

RV1 has demonstrated efficacy against vaccine serotype and nonvaccine serotype diseases. In Finland and Latin America, RV1 showed serotype-specific efficacy for G1P[8] 
of $91.8 \%(95 \% \mathrm{CI}: 74.1-98.4)$ and a combined efficacy against G3P[8], G4P[8], and G9P[8] of 87.3\% (95\% CI: 64.1-96.7). ${ }^{83}$ Too few cases of non-G1 or P[8] serotypes were isolated to determine efficacy against these groups. In Europe, the highest efficacy was seen against G1 serotypes, with the vaccine preventing $89.8 \%$ (95\% CI: 82.9-94.2) of any severe gastroenteritis. ${ }^{85}$ In Asia, RV1 prevented 100\% (95\% CI: 80.8-100) of G1 serotypes and 93.6\% (95\% CI: 74.7-99.3) of non-G1 serotypes of severe gastroenteritis. ${ }^{86}$ Several Brazilian studies have shown efficacy against nonvaccine serotypes. ${ }^{89,90}$ Among these, a case control study comparing children hospitalized with $\mathrm{G} 2 \mathrm{P}[4]$ rotavirus gastroenteritis to those hospitalized with acute respiratory infections demonstrated an efficacy of 77\% (95\% CI: 43-90) in infants aged 6-11 months..$^{90}$ However, the efficacy dropped to 15\% (95\% CI: -101 to 64$)$ in children older than 12 months. Further studies are needed to establish the efficacy of RV1 against serotypes that are neither G1 nor P[8].

Postintroduction impact of RV1 has been demonstrated in several countries. ${ }^{91-93}$ A retrospective case - control study in indigenous Australians during an outbreak of G9P[8] rotavirus found RV1 to be $84.5 \%$ (95\% CI: 23.4-96.9) effective at preventing hospitalized rotavirus infections. ${ }^{92}$ RV1 was introduced to the national immunization system in Brazil in 2006, with a vaccination coverage of $46.5 \%$ in 2006 and $78.3 \%$ in $2007 .{ }^{91}$ In 2006, there were $26 \%$ fewer hospitalizations in children aged younger than 1 year due to gastroenteritis compared with the average number of yearly hospitalizations from 1998 to 2005. In 2007, the hospitalization reduction was $48 \%$ compared with prevaccination levels. In 2007, a decrease in all-cause diarrheal disease was seen in children aged 1-5 years, reversing an increasing trend in gastroenteritis in this age group that had been seen in the past 10 years. Mexico introduced RV1 in 2007. In 2008, the incidence of diarrhea-related deaths decreased to 11.8 per 100,000 children younger than 5 years compared with 2003-2006 with an average of 18.1 deaths per 100,000 children; a rate reduction of 35\% (95\% CI: 29-39). This reduction continued though the 2009 rotavirus season. Such a dramatic reduction in diarrhea mortality is very promising for reducing mortality due to rotavirus infections.

Due to the previous association of rotavirus vaccination with intussusception, an extended intensive follow-up phase to assess severe side effects was built into most clinical trials. ${ }^{83,85,86}$ Over 75,000 children were followed in these studies for 31-100 days but no increased risk of intussusception was found. In fact, across all studies, there were significantly fewer serious adverse events noted in the vaccine recipients compared with placebo recipients. ${ }^{83,86}$ In addition, a study in East Asia reported no difference in nongastrointestinal serious adverse events in vaccine vs placebo recipients. ${ }^{86}$

\section{Lanzhou lamb}

A live, attenuated oral rotavirus vaccine (LLV) was developed by the Lanzhou Institute of Biological Products. The vaccine was developed by passing a wild-type group A serotype G10P[12] lamb rotavirus through primary calf kidney cells. After 37 passages, the virus was subsequently tested in several clinical studies. In 2000, LLR vaccine was licensed by China Drug Inspection and Management Bureau using a one-dose oral schedule. It is currently licensed in China to be given to children aged 2 to 36 months, followed by yearly boosters. ${ }^{94}$ However, the vaccine is relatively expensive in China, costing \$18.4 per dose; as a result, few children received more than one dose. ${ }^{95}$ Between 2001 and 2008, approximately 10,000,000 doses were administered in China. ${ }^{94}$ The vaccine is not routinely being used under China's national immunization program.

The strongest evidence for efficacy of LLV comes from a case control study in Guangzhou province comparing 838 children aged 2 months to 5 years hospitalized with rotavirus infections to 838 matched community controls. ${ }^{95}$ This study demonstrated a $73.3 \%$ (95\% CI: 61.2-81.6) efficacy of one dose of LLV against hospitalized rotavirus gastroenteritis. The efficacy was found to be higher in older children, with efficacy in 12-23 month olds found to be $80.9 \%$ (95\% CI: 65.4-89.4) compared with $60.0 \%$ (95\% CI: $28.6-77.6)$ in $2-11$ month olds. This may be due in-part to older children receiving vaccine at a later date, resulting in booster effect on an already present wild-type rotavirus response. A larger efficacy trial done in 4,000 infants aged from 6 to 24 months showed an efficacy against all-cause rotavirus gastroenteritis of $78 \% .{ }^{94}$ However, this study was not placebo controlled, and the results are not available in a peer-reviewed journal.

A nonrandomized cohort study in Guangzhou province in southern China following 102 vaccinated children and 145 unvaccinated children aged 6 months to 3 years for a total of 6 months found $53 \%$ fewer cases of rotavirus gastroenteritis in vaccinated children. ${ }^{96}$ In addition, disease was less severe; the average duration of disease was reduced by $24 \%$ $(P<0.001)$. A study comparing 225 children with rotavirus disease, 34 previously vaccinated and 191 unvaccinated, found a reduced duration $(P<0.001)$, severity $(P=0.041)$, and risk of hospitalization $(P=0.022)$ in the rotavirus vaccinated group. ${ }^{97}$ Immunologic studies among children aged 6-24 months before and after vaccination showed that LLR 
induced neutralizing antibody against rotavirus of all the four $\mathrm{G}$ types ranging from $40 \%$ to $70 \% .{ }^{94,98-100}$ However, these studies did not include non-vaccinated controls.

Available data suggests that there are no major safety concerns with LLR. Trials carried out in Beijing, Guangxi province, and Zhejiang province reported mild side effects, with $5.6 \%-8.2 \%$ of vaccinated children experiencing lowgrade fever and $0 \%-2.1 \%$ reporting high-grade fever. ${ }^{98-100}$ There has been one case report of intussusception following vaccination with LLR. ${ }^{101}$ Appropriately powered studies to assess differences in intussusceptions rates in vaccinated vs unvaccinated children have yet to be reported.

LLR has never been tested in a randomized, placebocontrolled phase III clinical trial, ${ }^{95}$ so the true efficacy of the vaccine is unknown. In all of the reported trials, the majority of children were vaccinated during or after the peak age for rotavirus disease. In China, $50 \%$ of rotavirus infections occur between the ages of 6 and 11 months. ${ }^{102}$ It is unknown whether vaccinated children had prior natural rotavirus infection, in which case LLV could be boosting an already present immune response. The efficacy of LLR in rotavirus-naive populations is unknown. Controlled studies in which children are vaccinated prior to peak age of rotavirus incidence are necessary to demonstrate its true efficacy and potential impact on rotavirus gastroenteritis.

\section{Vaccines under development}

In India, two live, cell line-adapted human viruses obtained from asymptomatic neonatal strains (116E and I321) recently underwent early clinical evaluation. ${ }^{103}$ Candidates using both vaccines were shown to be safe, with adverse event rates not statistically different in the vaccinated vs placebo groups. $116 \mathrm{E}$, a predominately human vaccine strain of serotype G9P[11], with the VP4 appearing to be a natural reassortant from a bovine strain of rotavirus, seems to be more promising. Immunologic evaluation showed a $73 \%$ serum IgA conversion rate compared with $20 \%$ in the placebo group. I321 was less immunogenic, resulting in 39\% seroconversion. A subsequent immunogenicity study of $116 \mathrm{E}$ in 93 and 91 children receiving $10^{4}$ and $10^{5}$ focus-forming units of vaccine virus, respectively, were compared with 184 placebo recipients. ${ }^{104}$ There was a $\geq 4$-fold increase in antirotavirus IgA titers in $66.7 \%$ of children receiving the lower dose and $62.1 \%$ of children receiving the higher dose after the first dose compared with $18 \%$ of placébo recipients. After 3 doses, $64.5 \%$ of infants receiving the lower dose and $89.7 \%$ of those receiving the higher dose had a $\geq 4$-fold increase in IgA compared with $25 \%$ of placebo recipients.
No increase in adverse events was found between vaccine and placebo recipients. This vaccine is scheduled to begin phase III efficacy trials in late 2010.

Early rotavirus vaccine development studies are underway in Vietnam in an effort to produce inexpensive rotavirus vaccine locally. Three human rotavirus strains (genotypes G1P[8], G1P[4], and G4P[6]) have been characterized for potential use in a live attenuated vaccine. ${ }^{105}$ The wild-type viruses for these strains have been passed more than 30 times, each through cell culture with the goal of developing an effective indigenously produced vaccine. The results of clinical trials are not yet available.

\section{Additional considerations Special populations}

As a part of the RV5 REST trial, 2,070 preterm infants (gestational age, 25-36 weeks; median age, 34 weeks) were evaluated in a substudy. ${ }^{106}$ Vaccine efficacy was $73.0 \%(95 \%$ CI: -2.2 to 95.2 ) against all rotavirus gastroenteritis for the first season of follow-up, indicating that prematurity does not drastically reduce vaccine effectiveness.

There is some concern about vaccine-associated rotavirus disease occurring in immunocompromised individuals. There was a report of vaccine-acquired rotavirus disease following RV5 administration in three infants with severe combined immunodeficiency (SCID); RV5 is now contraindicated in children with SCID. ${ }^{107}$ Further studies are needed to determine the safety and efficacy of both RV1 and RV5 in severely immunocompromised individuals. The effect of vaccination in HIV infected infants was studied in the RV1 clinical trials. A substudy of the trial in South Africa showed that there was no increase in mortality in HIV-positive vaccine recipients and no difference in adverse events. ${ }^{108}$

\section{Viral shedding}

For RV5, during REST and other phase III studies, potential fecal shedding between 4 and 6 days after each dose was monitored in nearly 250 children. In the 4- to 6-day period after the first dose, $8.9 \%$ of 360 RV5 recipients had detectable shedding by plaque assay of vaccine strains after the first dose. No shedding was detected after the second or third doses in vaccine recipients. ${ }^{109}$

For RV1, viral shedding was evaluated in early clinical trials. ${ }^{81,110,111}$ In one study of 213 infants, vaccine-type virus was shed in $28 \%$ of vaccine recipients 3 weeks after first immunization. ${ }^{82}$ After the second dose of vaccine, the proportion of shedding after 3 weeks was only $5 \%$. Studies of the concentration of vaccine virus in phase I and III trials have 
ranged from $10^{4}$ to $10^{6.4}$ plaque-forming units of vaccine virus to placebo. ${ }^{80}$ For both RV1 and RV5, the potential for disease transmission from viral shedding remains unclear.

\section{Breastfeeding}

Preliminary evidence suggests that the efficacy of RV 5 does not appear to be adversely affected by breastfeeding. The efficacy, assessed retrospectively from a cohort from the REST trial, against all rotavirus gastroenteritis for infants never breastfed, sometimes breastfed, or exclusively breastfed was 68.3\% (95\% CI: 46.1-82.1), 82.2\% (95\% CI: 72.3-89.0), and $68.0 \%$ (95\% CI: 53.8-78.3), respectively. ${ }^{112}$ Initial analysis of RV1 suggested that exclusive breastfeeding resulted in a $10 \%-12 \%$ decrease in vaccine take; however, response remained high in all groups. The clinical significance of the slight difference in immune response with exclusive breastfeeding remains unclear. ${ }^{111}$ Further trials are needed to establish the relationship between breastfeeding and vaccine efficacy in a variety of developing country settings.

\section{Concomitant administration with other vaccines}

Clinical trials have shown that oral rotavirus vaccine administration does not affect the immunogenicity of routine injected vaccines. ${ }^{113}$ There has been a fear of reduced immune response to rotavirus vaccine when given together with oral polio vaccine (OPV). In a study of 735 healthy infants in Latin America, children were randomized to receive RV5 concomitantly with OPV for 2 weeks prior to the OPV administration. Compared with staggered administration, the geometric mean titer of antirotavirus IgA was reduced by $46 \%$ with concomitant administration. However, the IgA titer in the concomitant-use group increased by $\geq 3$-fold between doses 1 and 3 in $93 \%$ of subjects, meeting the definition of noninferiority of immune response. ${ }^{114}$ For RV1, studies in South Africa and Bangladesh found no statistically significant difference in rotavirus IgA seroconversion rates when RV1 was administered with and without OPV. ${ }^{15,116}$ Therefore, it appears that there is no contraindication to giving oral rotavirus vaccines simultaneously with OPV.

\section{Dosing schedules}

The rotavirus vaccine schedule is timed with other recommended routine infant immunizations. RV5 is given at the same time as the primary diphtheria-tetanus-pertussis series, whereas RV1 is given with the first DTP dose, and either the 2 nd or 3 rd dose, depending on the country. ${ }^{117}$ The CDC and WHO recommend that the first dose be given between the ages of 6 and 15 weeks and final dose be given by 32 weeks due to a lack of safety and efficacy data outside this age range. ${ }^{71,118}$ In developing countries, a significant number of children receive their primary DTP series outside these age ranges. ${ }^{119}$ Catch-up campaigns in older children are a common strategy for rapidly reducing disease burden in newly vaccinated populations and maintaining coverage in children missed during routine immunization. ${ }^{120,121}$ Due to lack of safety data in older children, no catch-up campaigns have been attempted with rotavirus vaccines. Additional research on safety is needed in children immunized outside of the recommended age range to inform scheduling.

The long-term immunogenicity of rotavirus vaccine is unknown or is the effect of reduced transmission on the maintenance of immunity in older children and adults. In this sense, it is not known if a booster dose is needed to maintain protective immunity, however observations of reduced efficacy in older infants suggest protection, may wane. ${ }^{85,90}$ Ongoing longitudinal surveillance in recently introduced countries is necessary to determine long-term control strategies once infant disease is controlled.

\section{Serotype shift/replacement}

Rotavirus shows considerable geographic and temporal variation in serotypes. ${ }^{122,123}$ In addition, wild-type reassortments continually occur and have the potential to affect clinical disease. ${ }^{14}$ Because of this natural variance and the relatively short time period in which rotavirus vaccines have been in routine use, it is not yet clear of the impact that routine vaccination will have on the serotype profile of disease-causing rotavirus strains, and whether serotype replacement will occur over time. Although some studies have suggested a change in serotype profile following vaccine introduction, it is not clear whether this change is due to vaccination or part of the normal serotype variation seen with rotavirus disease. ${ }^{124}$ Ongoing surveillance is needed in both developed and developing country settings to assess the affect of routine vaccination on the changing serotype profile and what serotypes are responsible for human disease. ${ }^{14}$

\section{Relative effectiveness of RVI and RV5}

The difference in efficacy and effectiveness between RV1 and RV5 has not been studied in a head-to-head clinical trial but appear to be similar based upon reported effect against severe rotavirus disease from single-vaccine clinical trials. In addition, the efficacies of both RV1 and RV5 against severe rotavirus disease vary depending on the income status of the countries that hosted the studies (Figure 1). Although overlap 
exists between the efficacies estimated for each income group, and estimates likely vary based on the definition of severe gastroenteritis and length of follow-up, the overall trend is apparent; rotavirus vaccines are less effective in lower income settings. Lower efficacy in low-income settings is likely a combination of poor immunological response caused by malnutrition, other intestinal infections, and immunosuppression efficacy against other oral vaccines, as has been seen with the OPV. ${ }^{125}$ Across the listed studies, the average efficacy for high, upper middle, lower middle, and low income countries are $90 \%, 85 \%, 66 \%$, and $55 \%$, respectively. ${ }^{70,71,75,76,83-87,89,92,93,126}$

\section{Updated global estimations of rotavirus mortality}

The most recent global estimations for rotavirus mortality were calculated based on child diarrheal mortality figures from 2004. ${ }^{3}$ However, the Child Health Epidemiology Reference Group at the WHO recently released data showing a substantial decline in global diarrheal morality. ${ }^{127}$ To update global rotavirus morality estimates, we followed the methodology described by Parashar et $\mathrm{al}^{3}$ using 2008 countrylevel estimations of the number of deaths due to diarrhea in children aged younger than 5 years in $2008 .{ }^{127}$ The use of rotavirus vaccine was controlled in countries who introduced rotavirus vaccine prior to 2008 by reducing the proportion of diarrhea caused by rotavirus based on the rotavirus immunization coverage in 2008 or national estimates for coverage of three doses of diphtheria, pertussis, and tetanus vaccine (DTP-3) if rotavirus estimations were not available. ${ }^{117}$

Rates of deaths based on national income status (Table 2), region (Table 3), and national levels (Figures 2 and 3) are provided. In 2008, rotavirus was responsible for nearly 400,000 deaths (Table 2) or the deaths of approximately $4 \%$ of all children aged younger than 5 years. Varying the regional proportion of diarrheal deaths caused by rotavirus to the extreme estimates provided by Parashar et $\mathrm{al}^{3}$ gives low and high estimates of 320,000 and 440,000 deaths. As with

Table 2 Deaths due to rotavirus in children aged younger than 5 years, stratified by national income stratum

\begin{tabular}{lll}
\hline $\begin{array}{l}\text { Income } \\
\text { classification }\end{array}$ & Total & $\begin{array}{l}\text { Per } \mathbf{~ 0 0 , 0 0 0} \\
\text { children younger } \\
\text { than } \mathbf{5} \text { y }\end{array}$ \\
\hline High & 413 & 0.6 \\
Upper middle & 5,330 & 6.9 \\
Lower middle & 191,264 & 53.4 \\
Low & 189,106 & 137.9 \\
Total & 386,113 & 209.7 \\
\hline
\end{tabular}

previous estimates, the vast majority of deaths occur in low and lower middle income countries (Tables 2 and 3). Nine countries in Africa and Asia had more than 10,000 childhood rotavirus deaths in 2008 (Figure 2) while 30 countries had an incidence of rotavirus death greater than 100 per 100,000 children aged younger than 5 years (Figure 3 ).

\section{Potential impact of rotavirus vaccination on diarrheal mortality}

By applying the average efficacies from national income status to the regional rotavirus mortality and hospitalization estimates calculated by Parashar et $\mathrm{al}^{3}$ and to the country-level DTP-3 coverage in $2008,{ }^{128}$ we are able to estimate the potential impact of rotavirus vaccine. Country-level reductions were summed to predict the potential impact of the vaccines on rotavirus deaths and rates of deaths based on national income status (Table 4), region (Table 5), and national levels (Figures 4-6).

The potential impact of rotavirus vaccines is striking. If rotavirus vaccines were introduced at the current coverage of DTP-3, it would prevent approximately 166,000 deaths in children aged younger than 5 years each year globally (Table 4). Varying the regional proportion of diarrheal deaths caused by rotavirus to the extreme estimates provided by Parashar et $\mathrm{al}^{3}$ gives low and high estimates of 137,000 and 190,000 deaths prevented. Rotavirus vaccine is most effective in high-income countries, preventing approximately $71 \%$ of rotavirus deaths and $26 \%$ of diarrheal deaths. The two most populous upper middle income countries, Brazil and Mexico, already introduced rotavirus vaccines by 2008 . However, in upper middle income countries that have not yet introduced the vaccine, it would prevent $64 \%$ and $21 \%$ of rotavirus and diarrheal deaths. Vaccination at current DTP-3 levels in low and lower middle income countries would prevent less than $45 \%$ and $12 \%$ of rotavirus and diarrheal deaths, respectively, due to low efficacy and poor vaccine coverage in many countries. However, due to the large burden of diarrhea deaths in

Table 3 Deaths due to rotavirus in children aged younger than 5 years, stratified by region

\begin{tabular}{|c|c|c|}
\hline \multirow{2}{*}{$\frac{\text { World bank }}{\text { Region }}$} & \multicolumn{2}{|c|}{ Rotavirus deaths } \\
\hline & Total & $\begin{array}{l}\text { Per } 100,000 \text { children } \\
\text { younger than } 5 y\end{array}$ \\
\hline Africa & 236,519 & 155.8 \\
\hline Asia & 144,095 & 39.6 \\
\hline Europe & 167 & 0.4 \\
\hline $\begin{array}{l}\text { Latin America } \\
\text { and Caribbean }\end{array}$ & 5,000 & 8.8 \\
\hline North America & 3 & 0.0 \\
\hline Oceania & 328 & 11.6 \\
\hline
\end{tabular}




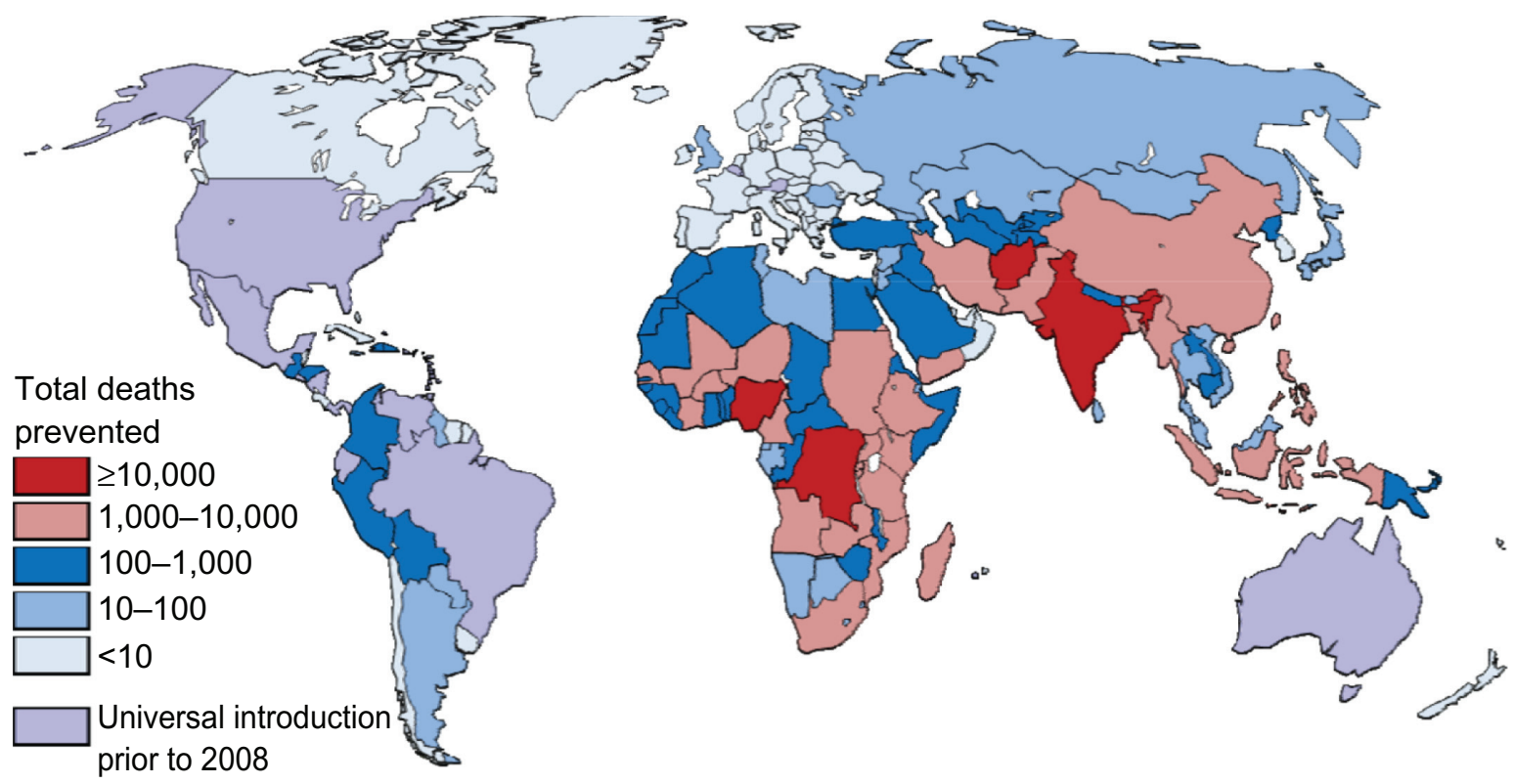

Figure 2 Estimated distribution of deaths caused by rotavirus diarrhea among children aged younger than 5 years.

these countries and large birth cohorts, $98 \%$ of preventable rotavirus deaths occur in low and lower middle income countries. Similarly, the highest incidence of preventable deaths is also seen in lower income countries. The number of preventable rotavirus deaths per 100,000 children in low-income countries is over 100 times than that seen in high-income countries.

Regionally, the potential impact of for rotavirus is highest in Africa and Asia, where $99 \%$ of preventable rotavirus deaths occur, which also have the higher incidence of preventable disease (Table 3). The highest absolute numbers of preventable deaths occur in the large, populous countries, such as India, Nigeria, the Democratic Republic of the Congo, Afghanistan, and Ethiopia (Figure 2), which account for 81,000 $(49 \%)$ of preventable deaths, in which India alone accounts for $16 \%$ of preventable deaths. Globally, 26 countries would prevent $>50$ deaths per 100,000 children younger than 5 years if rotavirus vaccine was introduced (Figure 3), with the majority of high-incidence countries located in Sub-Saharan Africa. Such a substantial reduction in deaths would go a long way towards helping countries to reach the Millennium Development Goal 4 of reducing child mortality.

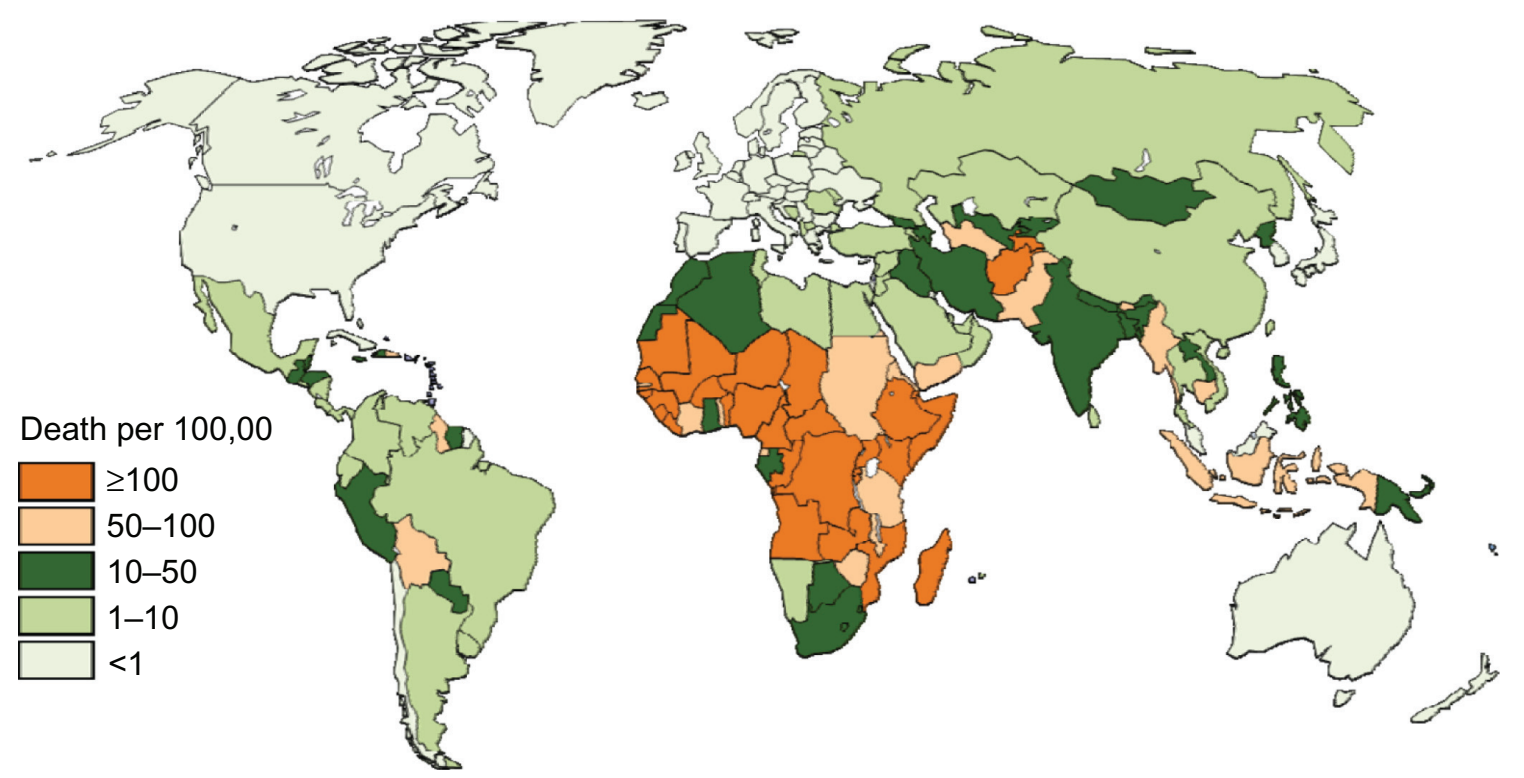

Figure 3 Estimated incidence of deaths caused by rotavirus diarrhea per 100,000 children aged younger than 5 years. 
Table 4 Impact of rotavirus vaccines on diarrheal deaths if introduced at level of DTP-3, stratified by national income stratum

\begin{tabular}{|c|c|c|c|c|}
\hline \multirow{2}{*}{$\begin{array}{l}\text { Income } \\
\text { classification }\end{array}$} & \multicolumn{2}{|c|}{ Diarrheal deaths prevented } & \multicolumn{2}{|c|}{ Proportion prevented } \\
\hline & Total & $\begin{array}{l}\text { Per } 100,000 \text { children } \\
\text { younger than } 5 y\end{array}$ & $\begin{array}{l}\text { Rotavirus } \\
\text { deaths, \% }\end{array}$ & $\begin{array}{l}\text { Diarrheal } \\
\text { deaths, \% }\end{array}$ \\
\hline High & 301 & 0.5 & 71 & 26 \\
\hline Upper middle & 3,121 & 4.0 & 44 & 15 \\
\hline Lower middle & 84,989 & 23.7 & 44 & 13 \\
\hline Low & 77,417 & 56.5 & 41 & 12 \\
\hline Total & 165,828 & 26.0 & 43 & 14 \\
\hline
\end{tabular}

Note: aWorld Bank 2008 classification. GNP per capita estimations from the US Government ${ }^{|3|}$ were used to approximate GNI for the Cook Islands, Nauru, Niue, and Tuvalu.

Although vaccine efficacy is lower in low-income settings, poor routine vaccination coverage reduces the potential impact of rotavirus vacation substantially. If vaccination with rotavirus reached $100 \%$ of children, 237,000 deaths (children aged younger than 5 years, would be averted each year; an additional 71,000 deaths averted compared with those using current DTP-3 coverage. In some countries, poor vaccine converge nearly negates the potential impact of rotavirus vaccines. In Chad, eg, the WHO estimates that only $20 \%$ of children received DTP-3 in 2008; combined with the efficacy seen in low-income countries, only $11 \%$ of rotavirus cases would be prevented. Similarly, many countries with high number of deaths due to rotavirus have poor vaccine coverage. India, which has a national DTP-3 coverage of $66 \%$, could prevent an additional 14,000 rotavirus deaths. Clearly, strengthening routine immunization is critical to maximize the impact of any new vaccine and ensure protection with traditional childhood immunization.

There are several reasons to believe that the estimations provided here are not entirely accurate. Parashar et $\mathrm{al}^{3}$ noted that more recent studies show a higher proportion of severe diarrhea caused by rotavirus in low-income countries compared with older studies, suggesting an underestimate in the proportion of diarrheal deaths caused by rotavirus. RV1 is administered following a two-dose schedule, so DTP-3 coverage estimations would underestimate impact for any country using RV1. Both RV1 and RV5 provide some protection with incomplete vaccination and as a result, the proportion of disease prevented would be higher in developing countries where a substantial number of children are only partially immunized. ${ }^{128}$ On the contrary, many developed countries have substantial delays in infant immunization, ${ }^{119}$ which would miss early rotavirus cases and reduce impact. Efficacy estimations do not include herd effects of immunization, which have been suggested to increase efficacy by $13 \%-25 \% .{ }^{129}$

\section{Conclusion}

Rotavirus is the leading cause of diarrheal morbidity and mortality globally, with nearly every child being infected in early childhood. Updated estimates indicate that over 380,000 rotavirus deaths occurred in 2008. Although treatment strategies exist, most deaths occur in settings where access to care is limited. Preventative strategies are limited, and sanitation-based strategies are not effective at preventing the spread of the virus. As a result, several rotavirus vaccines have been developed from animal, human, and hybrid strains. Two rotavirus vaccines have been licensed and used internationally, with several others being developed. Of the licensed vaccines, clinical trials have demonstrated excellent efficacy, although has generally been lower in low-income settings. Introductions with both the licensed vaccines have been promising and have shown an impact on rotavirus and all-cause diarrhea in both high-income and low-income settings. Using estimations of rotavirus and current immunization levels, rotavirus vaccine would prevent

Table 5 Impact of rotavirus vaccines on diarrheal deaths if introduced at level of DTP-3, stratified by region ${ }^{2}$

\begin{tabular}{|c|c|c|c|c|}
\hline \multirow{2}{*}{$\begin{array}{l}\text { World Bank } \\
\text { Region }\end{array}$} & \multicolumn{2}{|c|}{ Diarrheal deaths prevented } & \multicolumn{2}{|c|}{ Proportion prevented } \\
\hline & Total & $\begin{array}{l}\text { Per } 100,000 \text { children aged } \\
\text { younger than } 5 \text { years }\end{array}$ & $\begin{array}{l}\text { Rotavirus } \\
\text { deaths, \% }\end{array}$ & $\begin{array}{l}\text { Diarrheal } \\
\text { deaths, \% }\end{array}$ \\
\hline Africa & 95,623 & 63.0 & 40 & 12 \\
\hline Asia & 67,803 & 18.6 & 47 & 14 \\
\hline Europe & 136 & 0.4 & 80 & 31 \\
\hline $\begin{array}{l}\text { Latin America } \\
\text { and Caribbean }\end{array}$ & 2,145 & 3.8 & 31 & $\mathrm{II}$ \\
\hline Oceania & $|2|$ & 4.3 & 37 & 15 \\
\hline
\end{tabular}

Note: a North America has not been included because rotavirus vaccines were already reaching $88 \%$ of the children in the region. 


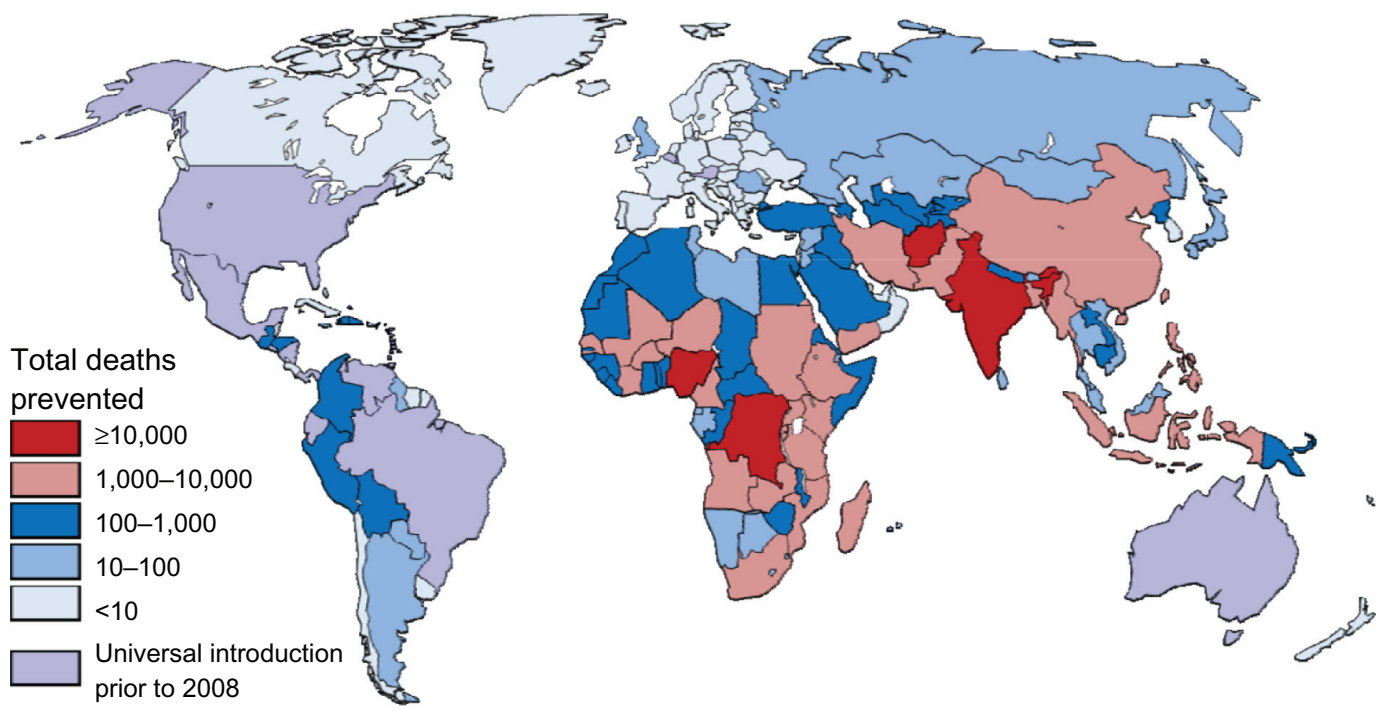

Figure 4 Total deaths prevented by rotavirus vaccine in children aged under 5 years if introduced at level of DTP-3.

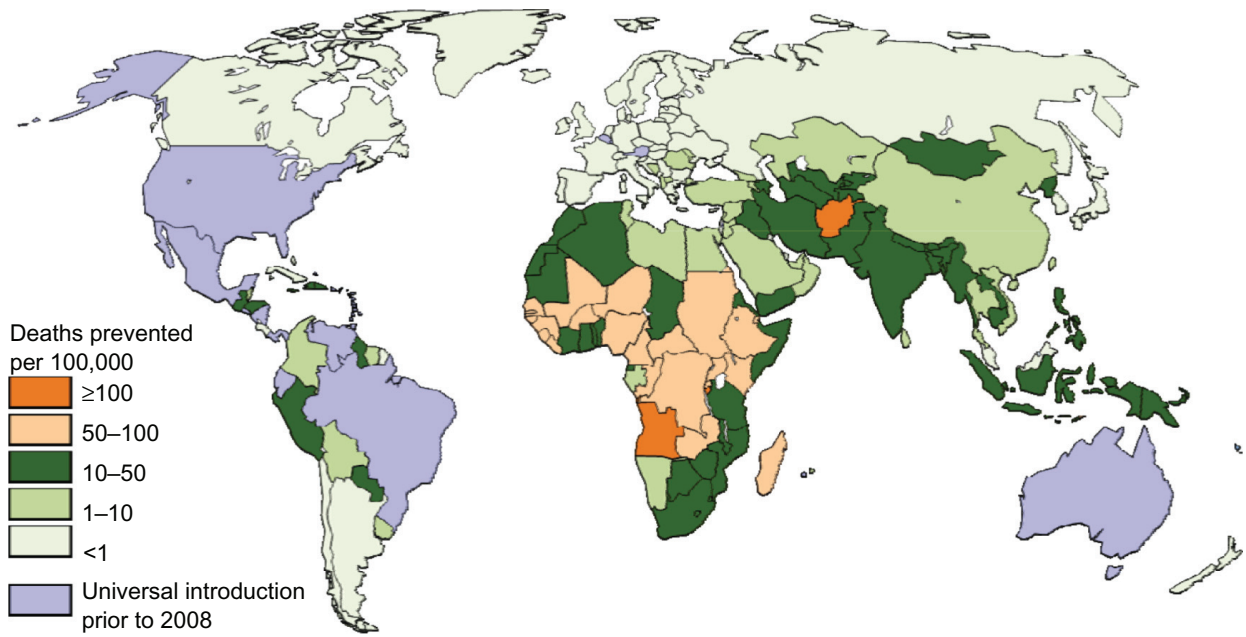

Figure 5 Total deaths prevented by rotavirus vaccine per 100,000 children aged younger than 5 years if introduced at level of DTP-3.

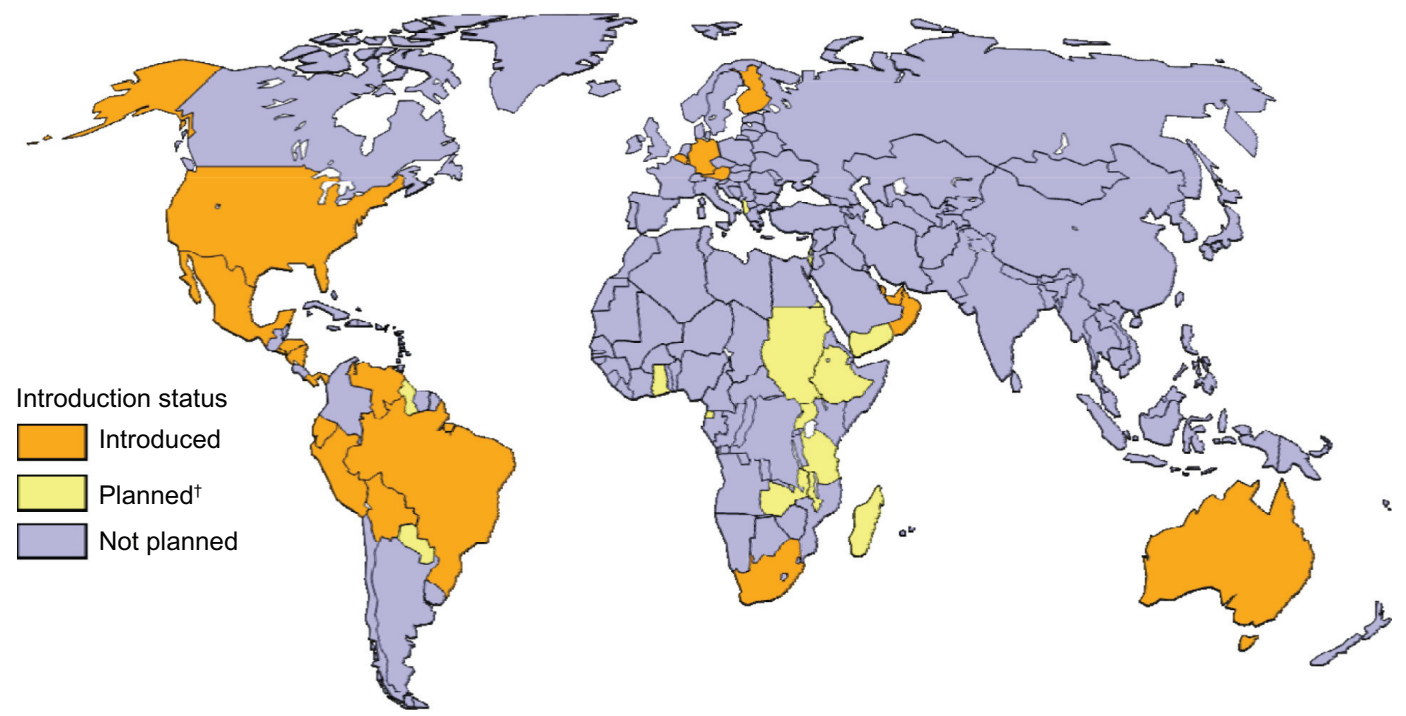

Figure 6 Global status of routine introduction of rotavirus vaccination. 
over 160,000 deaths yearly if introduced on a global level. The largest impact on mortality would be seen in low-income and middle-income countries, despite poor immunization coverage and lower efficacy. Thanks to international efforts, vaccine introduction is progressing in both high-income and low-income settings. However, focused efforts are needed on large, highest burden countries if rotavirus mortality is to be reduced dramatically.

\section{Disclosure}

The authors report no conflicts of interest in this work.

\section{References}

1. Glass RI, Kilgore PE, Holman RC, et al. The epidemiology of rotavirus diarrhea in the United States: surveillance and estimates of disease burden. J Infect Dis. 1996;174 Suppl 1:S5-S11.

2. Dennehy PH. Rotavirus vaccines: an overview. Clin Microbiol Rev. 2008;21:198-208.

3. Parashar UD, Burton A, Lanata C, et al. Global mortality associated with rotavirus disease among children in 2004. J Infect Dis. 2009; 200 Suppl 1:S9-S15.

4. Parashar UD, Gibson CJ, Bresse JS, et al. Rotavirus and severe childhood diarrhea. Emerg Infect Dis. 2006;12:304-306.

5. Bernstein DI. Rotavirus overview. Pediatr Infect Dis J. 2009;28: S50-S53.

6. Podewils LJ, Mintz ED, Nataro JP, et al. Acute, infectious diarrhea among children in developing countries. Semin Pediatr Infect Dis. 2004; $15: 155-168$.

7. Bresee JS, Glass RI, Ivanoff B, et al. Current status and future priorities for rotavirus vaccine development, evaluation and implementation in developing countries. Vaccine. 1999;17:2207-2222.

8. Velazquez FR, Matson DO, Calva JJ, et al. Rotavirus infections in infants as protection against subsequent infections. $N$ Engl $J$ Med. 1996;335:1022-1028.

9. Glass RI, Bhan MK, Ray P, et al. Development of candidate rotavirus vaccines derived from neonatal strains in India. J Infect Dis. 2005;192 Suppl 1:S30-S35.

10. Martella V, Banyai K, Matthijnssens J, et al. Zoonotic aspects of rotaviruses. Vet Microbiol. 2010;140:246-255.

11. Greenberg HB, Estes MK. Rotaviruses: from pathogenesis to vaccination. Gastroenterology 2009;136:1939-1951.

12. Santos N, Hoshino Y. Global distribution of rotavirus serotypes/genotypes and its implication for the development and implementation of an effective rotavirus vaccine. Rev Med Virol. 2005;15:29-56.

13. Clark HF, Offit PA, Parashar U, et al. Rotavirus vaccines. In: Plotkin SA, Orenstein WA, Offit PA, editors. Vaccines. Philadelphia, PA: Saunders Elsevier; 2008:715-734.

14. Matthijnssens J, Bilcke J, Ciarlet M, et al. Rotavirus disease and vaccination: impact on genotype diversity. Future Microbiol. 2009;4 1303-1316.

15. Payne DC, Szilagyi PG, Staat MA, et al. Secular variation in United States rotavirus disease rates and serotypes: implications for assessing the rotavirus vaccination program. Pediatr Infect Dis J. 2009;28: 948-953.

16. Zheng BJ, Chang RX, Ma GZ, et al. Rotavirus infection of the oropharynx and respiratory tract in young children. J Med Virol. 1991; 34: 29-37.

17. de Wit MA, Koopmans MP, van Duynhoven YT. Risk factors for norovirus, Sapporo-like virus, and group A rotavirus gastroenteritis. Emerg Infect Dis. 2003;9:1563-1570.

18. Santosham M, Yolken RH, Quiroz E, et al. Detection of rotavirus in respiratory secretions of children with pneumonia. $J$ Pediatr. 1983;103:583-585.

19. Desselberger U, Manktelow E, Li W, et al. Rotaviruses and rotavirus vaccines. Br Med Bull. 2009;90:37-51.
20. Ramig RF. Pathogenesis of intestinal and systemic rotavirus infection. J Virol. 2004;78:10213-10220.

21. Staat MA, Azimi PH, Berke T, et al. Clinical presentations of rotavirus infection among hospitalized children. Pediatr Infect Dis J. 2002;21: 221-227.

22. Intusoma U, Sornsrivichai V, Jiraphongsa C, et al. Epidemiology, clinical presentations and burden of rotavirus diarrhea in children under five seen at Ramathibodi Hospital, Thailand. J Med Assoc Thai. 2008;91: 1350-1355.

23. Cheng AC, McDonald JR, Thielman NM. Infectious diarrhea in developed and developing countries. J Clin Gastroenterol. 2005;39: 757-773.

24. WHO. The Treatment of Diarrhoea. A Manual for Physicians and Other Senior Health Workers. Geneva, Switzerland: WHO; 2005.

25. Duggan C, Santosham M, Glass RI. The management of acute diarrhea in children: oral rehydration, maintenance, and nutritional therapy. Centers for Disease Control and Prevention. MMWR Recomm Rep. 1992;41:1-20.

26. Bryce J, Boschi-Pinto C, Shibuya K, et al. WHO estimates of the causes of death in children. Lancet. 2005;365:1147-1152.

27. Guerrant RL, Kosek M, Lima AA, et al. Updating the DALYs for diarrhoeal disease. Trends Parasitol. 2002;18:191-193.

28. Niehaus MD, Moore SR, Patrick PD, et al. Early childhood diarrhea is associated with diminished cognitive function 4 to 7 years later in children in a northeast Brazilian shantytown. Am J Trop Med Hyg. 2002;66:590-593.

29. Lorntz B, Soares AM, Moore SR, et al. Early childhood diarrhea predicts impaired school performance. Pediatr Infect Dis J. 2006;25: 513-520.

30. Claeson M, Merson MH. Global progress in the control of diarrheal diseases. Pediatr Infect Dis J. 1990;9:345-355.

31. Hahn S, Kim S, Garner P. Reduced osmolarity oral rehydration solution for treating dehydration caused by acute diarrhoea in children. Cochrane Database Syst Rev. 2002;(1):CD002847.

32. Chung AW, Viscorova B. The effect of early oral feeding versus early oral starvation on the course of infantile diarrhea. J Pediatr. 1948;33:14-22.

33. Armitstead J, Kelly D, Walker-Smith J. Evaluation of infant feeding in acute gastroenteritis. J Pediatr Gastroenterol Nutr. 1989;8:240-244.

34. Hjelt K, Paerregaard A, Petersen W, et al. Rapid versus gradual refeeding in acute gastroenteritis in childhood: energy intake and weight gain. J Pediatr Gastroenterol Nutr. 1989;8:75-80.

35. Sandhu BK, Isolauri E, Walker-Smith JA, et al. A multicentre study on behalf of the European Society of Paediatric Gastroenterology and Nutrition Working Group on Acute Diarrhoea. Early feeding in childhood gastroenteritis. J Pediatr Gastroenterol Nutr. 1997;24:522-527.

36. Santosham M, Brown KH, Sack RB. Oral rehydration therapy and dietary therapy for acute childhood diarrhea. Pediatr Rev. 1987; 8:273-278.

37. Santosham M, Foster S, Reid R, et al. Role of soy-based, lactose-free formula during treatment of acute diarrhea. Pediatrics. 1985;76: 292-298.

38. WHO. Clinical Management of Acute Diarrhoea. New York: 2004. (WHO/UNICEF Joint Statement).

39. Patro B, Golicki D, Szajewska H. Meta-analysis: zinc supplementation for acute gastroenteritis in children. Aliment Pharmacol Ther. 2008; 28(6):713-723.

40. Lazzerini M, Ronfani L. Oral zinc for treating diarrhoea in children. Cochrane Database Syst Rev. 2008:CD005436.

41. Lukacik M, Thomas RL, Aranda JV. A meta-analysis of the effects of oral zinc in the treatment of acute and persistent diarrhea. Pediatrics. 2008;121:326-336.

42. Baqui AH, Black RE, El Arifeen S, et al. Effect of zinc supplementation started during diarrhoea on morbidity and mortality in Bangladeshi children: community randomised trial. BMJ. 2002;325:1059.

43. Bhandari N, Mazumder S, Taneja S, et al. Effectiveness of zinc supplementation plus oral rehydration salts compared with oral rehydration salts alone as a treatment for acute diarrhea in a primary care setting: a cluster randomized trial. Pediatrics. 2008;121:e1279-e1285.

44. Szajewska H, Skorka A, Ruszczynski M, et al. Meta-analysis: Lactobacillus GG for treating acute diarrhoea in children. Aliment Pharmacol Ther. 2007;25:871-881. 
45. Misra S, Sabui TK, Pal NK. A randomized controlled trial to evaluate the efficacy of lactobacillus GG in infantile diarrhea. J Pediatr. 2009;155:129-132.

46. Guandalini S. Probiotics for children with diarrhea: an update. J Clin Gastroenterol. 2008;42 Suppl 2:S53-S57.

47. Pulling M, Surawicz CM. Loperamide use for acute infectious diarrhea in children: safe and sound? Gastroenterology. 2008;134: 1260-1262.

48. Santos M, Maranon R, Miguez C, et al. Use of racecadotril as outpatient treatment for acute gastroenteritis: a prospective, randomized, parallel study. J Pediatr. 2009;155:62-67.

49. Isolauri E, Vahasarja V, Vesikari T. Effect of cholestyramine on acute diarrhoea in children receiving rapid oral rehydration and full feedings. Ann Clin Res. 1986;18:99-102.

50. Richards L, Claeson M, Pierce NF. Management of acute diarrhea in children: lessons learned. Pediatr Infect Dis J. 1993;12:5-9.

51. Alam NH, Ashraf H. Treatment of infectious diarrhea in children. Paediatr Drugs. 2003;5:151-165.

52. Rossignol JF, Abu-Zekry M, Hussein A, et al. Effect of nitazoxanide for treatment of severe rotavirus diarrhoea: randomised double-blind placebo-controlled trial. Lancet. 2006;368:124-129.

53. Teran CG, Teran-Escalera CN, Villarroel P. Nitazoxanide vs probiotics for the treatment of acute rotavirus diarrhea in children: a randomized, single-blind, controlled trial in Bolivian children. Int J Infect Dis. 2009; 13:518-523.

54. Matson DO, O’Ryan ML, Herrera I, et al. Fecal antibody responses to symptomatic and asymptomatic rotavirus infections. J Infect Dis. 1993; 167:577-583.

55. Fischer TK, Valentiner-Branth $\mathrm{P}$, Steinsland H, et al. Protective immunity after natural rotavirus infection: a community cohort study of newborn children in Guinea-Bissau, west Africa. J Infect Dis. 2002; 186:593-597.

56. Bishop RF, Barnes GL, Cipriani E, et al. Clinical immunity after neonatal rotavirus infection. A prospective longitudinal study in young children. N Engl J Med. 1983;309:72-76.

57. Chiba S, Yokoyama T, Nakata S, et al. Protective effect of naturally acquired homotypic and heterotypic rotavirus antibodies. Lancet. 1986; 2:417-421.

58. Clark HF, Dolan KT, Horton-Slight P, et al. Diverse serologic response to rotavirus infection of infants in a single epidemic. Pediatr Infect Dis. 1985;4:626-631.

59. Vesikari T, Isolauri E, Delem A, et al. Clinical efficacy of the RIT 4237 live attenuated bovine rotavirus vaccine in infants vaccinated before a rotavirus epidemic. J Pediatr. 1985;107:189-194.

60. Vesikari T, Isolauri E, D’Hondt E, et al. Protection of infants against rotavirus diarrhoea by RIT 4237 attenuated bovine rotavirus strain vaccine. Lancet. 1984;1:977-981.

61. De Mol P, Zissis G, Butzler JP, et al. Failure of live, attenuated oral rotavirus vaccine. Lancet. 1986;2:108.

62. Santosham M, Letson GW, Wolff M, et al. A field study of the safety and efficacy of two candidate rotavirus vaccines in a Native American population. J Infect Dis. 1991;163:483-487.

63. Clark HF, Offit PA, Ellis RW, et al. The development of multivalent bovine rotavirus (strain WC3) reassortant vaccine for infants. $J$ Infect Dis. 1996;174 Suppl 1:S73-S80.

64. Vesikari T, Rautanen T, Varis T, et al. Rhesus Rotavirus candidate vaccine. Clinical trial in children vaccinated between 2 and 5 months of age. Am J Dis Child. 1990;144:285-289.

65. Rennels MB, Glass RI, Dennehy PH, et al. Safety and efficacy of high-dose rhesus-human reassortant rotavirus vaccines - report of the National Multicenter Trial. United States Rotavirus Vaccine Efficacy Group. Pediatrics. 1996;97:7-13.

66. Perez-Schael I, Guntinas MJ, Perez M, et al. Efficacy of the rhesus rotavirus-based quadrivalent vaccine in infants and young children in Venezuela. N Engl J Med. 1997;337:1181-1187.

67. Murphy TV, Gargiullo PM, Massoudi MS, et al. Intussusception among infants given an oral rotavirus vaccine. $N$ Engl J Med. 2001;344: 564-572.

68. Chandran A, Santosham M. RotaTeq: a three-dose oral pentavalent reassortant rotavirus vaccine. Expert Rev Vaccines. 2008;1475-1480.
69. Vesikari T, Matson DO, Dennehy P, et al. Safety and efficacy of a pentavalent human-bovine (WC3) reassortant rotavirus vaccine. N Engl J Med. 2006;354:23-33.

70. Vesikari T, Itzler R, Matson DO, et al. Efficacy of a pentavalent rotavirus vaccine in reducing rotavirus-associated health care utilization across three regions (11 countries). Int J Infect Dis. 2007;11 Suppl 2: S29-S35.

71. Rotavirus vaccines:an update. Wkly Epidemiol Rec. 2009;84:533-540.

72. Chang CC, Chang MH, Lin TY, et al. Experience of pentavalent humanbovine reassortant rotavirus vaccine among healthy infants in Taiwan. J Formos Med Assoc. 2009;108:280-285.

73. Reduction in rotavirus after vaccine introduction - United States, 2000-2009. MMWR Morb Mortal Wkly Rep. 2009;58:1146-1149.

74. Wang FT, Mast TC, Glass RJ, et al. Effectiveness of the pentavalent rotavirus vaccine in preventing gastroenteritis in the United States. Pediatrics. 2010;125:e208-e213.

75. Boom JA, Tate JE, Sahni LC, et al. Effectiveness of pentavalent rotavirus vaccine in a large urban population in the United States. Pediatrics. 2010;125:e199-e207.

76. Patel M, Pedreira C, De Oliveira LH, et al. Association between pentavalent rotavirus vaccine and severe rotavirus diarrhea among children in Nicaragua. JAMA. 2009;301:2243-2251.

77. Orozco M, Vasquez J, Pedreira C, et al. Uptake of rotavirus vaccine and national trends of acute gastroenteritis among children in Nicaragua. J Infect Dis. 2009;200 Suppl 1:S125-S130.

78. Belongia EA, Irving SA, Shui IM, et al. Real-time surveillance to assess risk of intussusception and other adverse events after pentavalent, bovine-derived rotavirus vaccine. Pediatr Infect Dis J. 2010;29:1-5.

79. Bernstein DI. Live attenuated human rotavirus vaccine, Rotarix. Semin Pediatr Infect Dis. 2006;17:188-194.

80. O'Ryan M, Linhares AC. Update on Rotarix: an oral human rotavirus vaccine. Expert Rev Vaccines. 2009;8:1627-1641.

81. Bernstein DI, Smith VE, Sherwood JR, et al. Safety and immunogenicity of live, attenuated human rotavirus vaccine 89-12. Vaccine. 1998; 16:381-387.

82. Bernstein DI, Sack DA, Rothstein E, et al. Efficacy of live, attenuated, human rotavirus vaccine $89-12$ in infants: a randomised placebocontrolled trial. Lancet. 1999;354:287-290.

83. Ruiz-Palacios GM, Perez-Schael I, Velazquez FR, et al. Safety and efficacy of an attenuated vaccine against severe rotavirus gastroenteritis. $N$ Engl J Med. 2006;354:11-22.

84. Vesikari T, Karvonen A, Puustinen L, et al. Efficacy of RIX4414 live attenuated human rotavirus vaccine in Finnish infants. Pediatr Infect Dis J. 2004;23:937-943.

85. Vesikari T, Karvonen A, Prymula R, et al. Efficacy of human rotavirus vaccine against rotavirus gastroenteritis during the first 2 years of life in European infants: randomised, double-blind controlled study. Lancet. 2007;370:1757-1763.

86. Phua KB, Lim FS, Lau YL, et al. Safety and efficacy of human rotavirus vaccine during the first 2 years of life in Asian infants: randomised, double-blind, controlled study. Vaccine. 2009;27:5936-5941.

87. Madhi SA, Cunliffe NA, Steele D, et al. Effect of human rotavirus vaccine on severe diarrhea in African infants. N Engl J Med. 2010;362: 289-298.

88. Tate JE, Patel MM, Steele AD, et al. Global impact of rotavirus vaccines. Expert Rev Vaccines. 2010;9:395-407.

89. Gurgel RG, Bohland AK, Vieira SC, et al. Incidence of rotavirus and allcause diarrhea in northeast Brazil following the introduction of a national vaccination program. Gastroenterology. 2009;137:1970-1975.

90. Correia JB, Patel MM, Nakagomi O, et al. Effectiveness of monovalent rotavirus vaccine (Rotarix) against severe diarrhea caused by serotypically unrelated G2P[4] strains in Brazil. J Infect Dis. 2010;201: 363-369.

91. Lanzieri TM, Costa I, Shafi FA, et al. Trends in hospitalizations from all-cause gastroenteritis in children younger than 5 years of age in Brazil before and after human rotavirus vaccine introduction, 1998-2007. Pediatr Infect Dis J. 2010:29.

92. Snelling TL, Schultz R, Graham J, et al. Rotavirus and the indigenous children of the Australian outback: monovalent vaccine effective in a high-burden setting. Clin Infect Dis. 2009;49:428-431. 
93. Meeting of the immunization Strategic Advisory Group of Experts, Apr 2009 - conclusions and recommendations. Wkly Epidemiol Rec. 2009;84:220-236.

94. Hong Wang ZD. Research and progress of oral live rotavirus vaccine. Chinese Journal of Virology. 2009:25.

95. Fu C, Wang M, Liang J, et al. Effectiveness of Lanzhou lamb rotavirus vaccine against rotavirus gastroenteritis requiring hospitalization: a matched case-control study. Vaccine. 2007;25:8756-8761.

96. Li H. Research on effectiveness of oral rotavirus live vaccine. Medical Information. 2009:22.

97. Jinying Xie YL. Clinical observation on prevention and protection of rotavirus vaccine against rotavirus caused enteritis. International Medicine and Health Guidance News. 2009:15.

98. Fuqiang Gong XZ. Observation on safety and efficacy of oral rotavirus vaccine. Prog in Microbiol Immunol. 2005:33.

99. Liu Dong-lei YJ, Li An, et al. Observation of immunization effect and reverse reaction of rotavirus vaccine. Chinese Journal of Vaccines and Immunization. 2002:8.

100. Zhang X-x. Epidemiology of Rotavirus Infections and Its Vaccine Research. Occupation and Health. 2009:25.

101. Zhang K. One case report of Intussuception after vaccination with live attenuated oral rotavirus vaccine. Chinese Journal of Vaccines and Immunization. 2009:15.

102. Duan ZJ, Liu N, Yang SH, et al. Hospital-based surveillance of rotavirus diarrhea in the people's Republic of China, Aug 2003-Jul 2007. J Infect Dis. 2009;200 Suppl 1:S167-S173.

103. Bhandari N, Sharma P, Glass RI, et al. Safety and immunogenicity of two live attenuated human rotavirus vaccine candidates, $116 \mathrm{E}$ and I321, in infants: results of a randomised controlled trial. Vaccine. 2006; 24:5817-5823.

104. Bhandari N, Sharma P, Taneja S, et al. A dose-escalation safety and immunogenicity study of live attenuated oral rotavirus vaccine $116 \mathrm{E}$ in infants: a randomized, double-blind, placebo-controlled trial. $J$ Infect Dis. 2009;200:421-429.

105. Luan le T, Trang NV, Phuong NM, et al. Development and characterization of candidate rotavirus vaccine strains derived from children with diarrhoea in Vietnam. Vaccine. 2009;27 Suppl 5: F130-F138.

106. Goveia MG, Rodriguez ZM, Dallas MJ, et al. Safety and efficacy of the pentavalent human-bovine (WC3) reassortant rotavirus vaccine in healthy premature infants. Pediatr Infect Dis J. 2007;26: 1099-1104.

107. Patel NC, Hertel PM, Estes MK, et al. Vaccine-acquired rotavirus in infants with severe combined immunodeficiency. $N$ Engl J Med. 2010;362:314-319.

108. Steele AD, Cunliffe N, Tumbo J, et al. A review of rotavirus infection in and vaccination of human immunodeficiency virus-infected children. J Infect Dis. 2009;200 Suppl 1:S57-S62.

109. Dennehy PH. Rotavirus vaccines - an update. Vaccine. 2007;25: 3137-3141.

110. Vesikari T, Karvonen A, Korhonen T, et al. Safety and immunogenicity of RIX4414 live attenuated human rotavirus vaccine in adults, toddlers and previously uninfected infants. Vaccine. 2004;22: 2836-2842.

111. Dennehy PH, Brady RC, Halperin SA, et al. Comparative evaluation of safety and immunogenicity of two dosages of an oral live attenuated human rotavirus vaccine. Pediatr Infect Dis J. 2005;24:481-488.

112. Goveia MG, DiNubile MJ, Dallas MJ, et al. Efficacy of pentavalent human-bovine (WC3) reassortant rotavirus vaccine based on breastfeeding frequency. Pediatr Infect Dis J. 2008;27:656-658.

Biologics: Targets \& Therapy

\section{Publish your work in this journal}

Biologics: Targets \& Therapy is an international, peer-reviewed journal focusing on the patho-physiological rationale for and clinical application of Biologic agents in the management of autoimmune diseases, cancers or other pathologies where a molecular target can be identified This journal is indexed on PubMed Central, CAS, EMBase, Scopus
113. Dennehy PH, Bertrand HR, Silas PE, et al. Coadministration of RIX4414 oral human rotavirus vaccine does not impact the immune response to antigens contained in routine infant vaccines in the United States. Pediatrics. 2008;122:e1062-e1066.

114. Ciarlet M, Sani-Grosso R, Yuan G, et al. Concomitant use of the oral pentavalent human-bovine reassortant rotavirus vaccine and oral poliovirus vaccine. Pediatr Infect Dis J. 2008;27:874-880.

115. Zaman K, Sack DA, Yunus M, et al. Successful co-administration of a human rotavirus and oral poliovirus vaccines in Bangladeshi infants in a 2-dose schedule at 12 and 16 weeks of age. Vaccine. 2009;27:1333-1339.

116. Steele AD, De Vos B, Tumbo J, et al. Co-administration study in South African infants of a live-attenuated oral human rotavirus vaccine (RIX4414) and poliovirus vaccines. Vaccine. 2008.

117. WHO. WHO vaccine-preventable diseases: monitoring system, 2009 global summary. Geneva, Switzerland: WHO; 2009. (GPO no. WHO/ IVB/2009)

118. Parashar UD, Alexander JP, Glass RI. Prevention of rotavirus gastroenteritis among infants and children. Recommendations of the Advisory Committee on Immunization Practices (ACIP). MMWR Recomm Rep. 2006;55:1-13.

119. Clark A, Sanderson C. Timing of children's vaccinations in 45 low-income and middle-income countries: an analysis of survey data. Lancet. 2009;373:1543-1549.

120. Hamlin J, Senthilnathan S, Bernstein HH. Update on universal childhood immunizations. Curr Opin Pediatr. 2008;20:483-489.

121. Noakes K, Salisbury D. Immunization campaigns in the UK. Curr Top Microbiol Immunol. 2006;304:53-70.

122. Kang JO, Kilgore P, Kim JS, et al. Molecular epidemiological profile of rotavirus in South Korea, Jul 2002 through Jun 2003: emergence of G4P[6] and G9P[8] strains. J Infect Dis. 2005;192 Suppl 1:S57-S63.

123. Martini IJ, Gennari GM, Martins SS, et al. Changing distribution of human rotavirus serotypes during two epidemic outbreaks of gastroenteritis in Campinas, Sao Paulo, Brazil, 2003-2004: detection of G6 strains. J Clin Virol. 2008;43:244-246.

124. Nakagomi T, Cuevas LE, Gurgel RG, et al. Apparent extinction of non-G2 rotavirus strains from circulation in Recife, Brazil, after the introduction of rotavirus vaccine. Arch Virol. 2008;153:591-593.

125. Paul Y. Oral polio vaccines and their role in polio eradication in India. Expert Rev Vaccines. 2009;8:35-41.

126. Muhsen K, Shulman L, Kasem E, et al. Effectiveness of rotavirus vaccines for prevention of rotavirus gastroenteritis-associated hospitalizations in Israel: a case-control study. Hum Vaccin 2010;6.

127. Black RE, Cousens S, Johnson HL, et al. Global, regional, and national causes of child mortality in 2008: a systematic analysis. Lancet. Epub 2010 May 11

128. WHO. WHO vaccine-preventable diseases: monitoring system, 2008 global summary. Geneva, Switzerland:WHO; 2008. (GPO no. WHO/ IVB/2008).

129. Van Effelterre T, Soriano-Gabarro M, Debrus S, et al. A mathematical model of the indirect effects of rotavirus vaccination. Epidemiol Infect. 2010;138:884-897.

130. Gracey M. Diarrhoea in Australian Aborigines. Aust J Public Health. 1992;16:216-225.

131. The World Factbook 2009. Washington, DC: Central Intelligence Agency; 2009.

\section{Dovepress}

and the Elsevier Bibliographic databases. The manuscript management system is completely online and includes a very quick and fair peerreview system, which is all easy to use. Visit http://www.dovepress. $\mathrm{com} /$ testimonials.php to read real quotes from published authors. 